\title{
El debate entre liberales y conservadores en Centroamérica. Distintos medios para un objetivo común, la construcción de una república de ciudadanos $(1821-1900)$
}

SONIA ALDa MEJías ${ }^{1}$

\begin{abstract}
RESUMEN
ABSTRACT

La aspiración común de los liberales y The common goal of liberals and los conservadores en Centroamérica en el siglo XIX fue construir una república representativa de ciudadanos instruidos y formados. La diferencia radico en cómo realizar este proceso de transformación. Este debate determinó en buena parte la evolución de la ciudadanía y los diferentes modelos de república implantados a lo largo del siglo XIX en la región. Mediante el estudio comparado de la legislación electoral y los textos constitucionales se conservatives in Centroamerica during the nineteeth century was the construction of a representative republic constituted by formed and instructed citizens. The difference among them was how to perform this transformation process. The debate determined basically the evolution of citizenship and the distinctive models of republican order implanted during the century. Through the comparative analysis of electoral legislation
\end{abstract}

Adscrita al Departamento de Historia Contemporánea (UNED), mediante la beca de investigación postdoctoral concedida por la Consejeria de Educación y Cultura de la Comunidad Autónoma de Madrid. Este trabajo se integra en el proyecto de investigación PB97-0080. 
comprueba la existencia de tres modelos de república diferentes en coherencia con la forma en que ambos grupos concibieron la forma, el ritmo y los medios para lograr un objetivo compartido por ambos.

PALABRAS CLAVE Centroamérica, república representativa, conservadores, liberales, ciudadania, electorado, civilización. and the Cartas Magnas can be proved the existence of three different republican models according with the common goal of the two already mentioned groups.

\section{KEY WORDS}

Central America, representative republic, liberals, conservatives, citizenship, electors, civilization.

\section{INTRODUCCIÓN}

Desde la Independencia de Centroamérica en 1821, los liberales y los conservadores iniciaron un debate permanente en torno a los medios, la forma y el ritmo en que debía construirse una república integrada por ciudadanos conscientes e instruidos al modo de las "naciones civilizadas". La forma de llevar a cabo la transformación de súbditos en ciudadanos está latente en los apasionados y encendidos debates mantenidos entre unos y otros, si bien compartieron una concepción socio-política común, cuya legitimidad radicaba en los dictados de la voluntad popular. Este debate determinó la evolución de la ciudadanía y los diferentes modelos de repúblicas implantados a lo largo del siglo en la región. Como se pretenderá demostrar bajo una perspectiva comparativa, a lo largo del siglo XIX hay una relación directa entre la concepción de cambio y transformación de los liberales y de los conservadores y la evolución de la ciudadanía y del universo electoral.

El mayor obstáculo para construir una república "civilizada" fue la absoluta ignorancia de "las masas" y la heterogeneidad de su población. La pretensión de lograr una población uniformada bajo la cultura occidental, sinónimo de civilización, y por tanto de ciudadanos conscientes y responsables, chocó permanentemente con la realidad étnico-cultural de la población centroamericana, integrada mayoritariamente por población mestiza y en menor medida indígena. En el caso de Guatemala la relación fue inversa pues la población indígena era y es mayoritaria. A partir de esta percepción $\mathrm{de}$ la sociedad, las diferencias estuvieron marcadas por la forma y los medios en que debía lograrse la civilización de la población y por tanto la construcción de la república. Esta diferencia perfiló, dependiendo del pre- 
dominio político de los liberales o de los conservadores, distintos modelos de repúblicas como muestran los textos constitucionales, en los que se amplió o restringió la definición de ciudadanía y/o la participación electoral, en coherencia con el proyecto de transformación defendido por unos y otros.

De acuerdo a esta relación se ha distinguido tres periodos marcados por un modelo de república determinada. Durante la Federación centroamericana, de 1824 a 1838 , bajo el predominio político de los liberales los derechos civiles y políticos de la ciudadanía se extendieron a la mayoría de la población, ya que en coherencia con su concepción de transformación se entendió que mediante el ejercicio práctico de estos derechos sería posible convertir a la población en ciudadanos responsables y conscientes. Tras la disolución del pacto federal y la constitución de las cinco repúblicas centroamericanas, los gobiernos conservadores y liberales moderados que accedieron al poder restringieron la definición de ciudadanía, en términos generales y limitaron el universo electoral, así como el sector de población que podía ser elegido. El establecimiento de una república restrictiva estuvo en coherencia con su proyecto de transformación, ya que entendieron que sólo bajo cambios progresivos y moderados sería posible la formación de la población y entonces generalizar los derechos ciudadanos. La última etapa considerada comprende el período entre 1870 y 1900 , período en el que de nuevo acceden de forma generalizada los liberales al poder. El intento de encontrar un punto intermedio respecto a los planteamientos anteriores y en coherencia con el concepto de cambio adoptado, bajo la influencia del positivismo, favoreció en la década de los años setenta la ampliación de la ciudadanía. A partir de este período de acuerdo a las repúblicas se adaptará prácticamente el sufragio universal masculino o como en Costa Rica y Guatemala a principios de siglo xx una evolución restrictiva. Es de destacar en esta evolución la importante influencia de la Constitución de Cádiz en la definición de la ciudadanía en toda la región a lo largo del siglo.

La existencia de un objetivo común orientado a la construcción de una república al modo de las "naciones civilizadas" no significa negar ni restar importancia a las diferencias que separaron a liberales y conservadores. La forma distinta en la que entendieron la transformación social y política de la sociedad en cuanto al ritmo, la forma y los medios empleados dieron lugar a repúblicas muy diferentes e incluso contrapuestas como pone en evidencia los diferentes modelos de república establecidos a lo largo del siglo.

La interpretación del presente artículo se alinea con estudios que han intentado superar la continuidad de la versión ofrecida por la historia política de finales del siglo XIX. Tradicionalmente se ha presentado a los liberales y a los 
conservadores como dos grupos antagónicos, acabando por generar la repetición de un esquema simplificado. A partir del mismo, la mayoría de los historiadores posteriores han pretendido ver en los liberales y sus proyectos un programa democrático, con preocupaciones y ambiciones transformadoras, más propio del siglo $x \times$ que del período histórico considerado. Por contra, los conservadores encarnarían el inmovilismo y los antecedentes de la derecha más reaccionaria. Esta descontextualización distorsionó las concepciones políticas del siglo $\mathrm{XIX}$, presentadas como una permanente tensión entre el progreso y el inmovilismo o entre el avance y la reacción, sin considerar cuál fue el proyecto de sociedad que liberales y conservadores pretendieron implantar desde la Independencia, de acuerdo a una legitimidad y a unos valores republicanos que en el discurso no negaron unos ni otros. Muy al contrario un partido y otro pretendieron apropiarse de ellos en exclusiva.

\section{DIFERENCIAS EN MEDIOS PARA UNA FINALIDAD COMÚN: LA CONSTRUCCIÓN DE UNA REPÚBLICA DE CIUDADANOS CIVILIZADOS}

Desde fines del siglo xIx, la eficacia de la propaganda liberal generalizó un esquema básico de las diferencias políticas, e incluso ideológicas, que separaron a liberales y conservadores. Bajo el prisma liberal estas diferencias se resumían en una presentación polarizada, en la que los "serviles" (conservadores) se situaban ideológicamente al rnargen y en contra de los presupuestos liberales y republicanos. Su objetivo se reducia a la restauración de la sociedad colonial. Por contra, los liberales lucharon por establecer una república representativa, impulsada por la autenticidad de sus convicciones democráticas ${ }^{1}$. Esta versión fue respondida por diferentes historiadores a partir de la primera mitad del siglo xx, adoptando la misma versión histórica, en este caso para criticar a los liberales. Así se responsabilizaba a los "fiebres" (liberales) del atraso y crisis en que se encontraba Guatemala y el resto de la región centroamericana, al pretender imponer, por la fuerza, proyectos quiméricos y extraños a su realidad social y política. Las consecuencias de todo ello afectaban al desarrollo de la región en pleno siglo $x x^{2}$.

\footnotetext{
L. Montufar, Reseña histórica de Centroamérica, Guatemala, 1878-88; H. Bancroft, History of Central America, San Francisco, 1886-87.

A. Batres, La América Central ante la Historia, (1915-1949), Guatemala, 1949; Cl. Marro Quin, Morazán y Carrera, Guatemala, 1965; M. CORONADO. Apuntes histórico-guatemalenses, Guatemala, 1975.
} 
Si bien se mantuvo la influencia de aquella visión, algunos trabajos posteriores al formular nuevas preguntas superaron esta historia tradicional y descriptiva. La revisión de la interpretación tradicional cuestiona la visión maniquea que presenta dos únicos proyectos contrapuestos, el progresismo radical y la reacción ultramontana, tanto en el pensamiento como en la práctica política, sin considerar las coincidencias ${ }^{3} 0$ la existencia de opciones moderadas ${ }^{4}$. Además la adopción literal de las proclamas revolucionarias de los liberales, sea para alabarlas o para criticarlas, ha impedido ver que unos y otros no fueron tan divergentes. Buena parte de las políticas liberales de fin de siglo fueron iniciadas por los conservadores. A su vez éstos aprovecharon o continuaron acciones de gobierno realizadas por los liberales ${ }^{5}$.

Junto a los estudios centrados en las políticas concretas de liberales y conservadores, el análisis del discurso proporciona nuevas aportaciones a las recientes investigaciones. El estudio de la prensa permite comprobar que los estereotipos asumidos provienen de las expresiones y acusaciones que un partido y otro utilizaron para desprestigiar al contrario y reforzar su propia legitimidad, según los presupuestos y concepciones que organizaban políticamente a la sociedad. Con esta estrategia, cada partido pretendía ser el auténtico y único representante de la voluntad popular y de los valores republicanos, lo que generó una imagen forzosamente polarizada. Las mismas denominaciones de fiebres y serviles formaban parte de esta dinámica. Estos eran los calificativos con los que se acusaba mutuamente cada facción o partido ${ }^{6}$.

Desde 1820, con el restablecimiento de la Constitución de Cádiz de 1812, tras el pronunciamiento de Riego en España, los centroamericanos

3 Ch. HALE, El liberalismo mexicano en la época de Mora, 1821-1853, México, 1972.

4 J. Z. VAZOUEZ, "Liberales y conservadores en México: diferencias y similitudes", Estudios Interdisciplinarios de América Latina y El Caribe, n. 1 (enero-junio 1997), págs. 19-20.

5 L. Gudmundsun, "Sociedad y política (1840-1871)", en H. PEREz (ed.), Historia General de Centroamérica, Madrid, 1993, t. III, págs. 203-254. En este mismo sentido O. ZELAYA, “Sociedad y política: Gobiernos liberales conservadores en el siglo XIX (1838-1875)" en O. ZELAYA (comp.), Lecturas de Historia de Honduras. Antologia, Tegucigalpa, 1998, págs. 224-225; M. ARgUETA, La primera generación liberal: fallas y aciertos (1826-1842), Tegucigalpa, 1999; R. L. WOODWARD, Rafael Carrera and the Emergence of the Republic of Guatemala, 1821-1871, Georgia, 1993, tras una minuciosa revisión. llega a conclusiones similares al examinar la política general del período conservador en Guatemala (1839-1871). El estudio de J. CASTELLANos, Café y campesinos en Guatemala, 1538-1879, Guatemala, 1987, muestra que los conservadores iniciaron los cultivos de café, fuente principal de riqueza a partir de 1871.

6 El Editor Constitucional, 24/VI/1820. El término de partido es utilizado en la época y se identifica con aquella agrupación que mira por el bien general, mientras que la facción solo actúa impulsada por intereses egoístas y particulares. De ahi que cada agrupación se identifique como partido pero se acuse de faccionalismo. 
se dividieron en liberales y conservadores. En las elecciones para elegir diputados a Cortes, Diputación Provincial y cargos municipales, como exigía la Constitución uno y otro grupo fue denominado como "cacos" (liberales) y "gases" o "bacos" (conservadores) ?. Tras la decisión de separarse de la metrópoli, el 15 de septiembre de 1821, desde Ciudad de Guatemala se declaró la anexión de Centroamérica al Imperio mexicano de Iturbide, en enero de 1822. En este periodo se distinguieron como imperiales (conservadores) y republicanos (liberales) según estuvieran a favor o en contra de dicha anexión. Con la disolución del Imperio de Iturbide, en febrero de 1823, este enfrentamiento desapareció. En 1823 tras la instalación de una Asamblea Constituyente integrada por representantes de las provincias centroamericanas se agruparon en centralistas, (conservadores) partidarios de un sistema unitario o federalistas (liberales), partidarios de una estructura federal ${ }^{8}$. Con la decisión final de adoptar la estructura federal en diciembre de 1823, los términos más comunes aplicados para un partido y otro fueron "fiebres" y "serviles". Una vez disuelta la federación en 1838 dicha división se mantuvo hasta finales de siglo, en las repúblicas centroamericanas $^{9}$. A través de dos periódicos, El Editor Constitucional y El Amigo de la Patria, publicados en Ciudad de Guatemala, es posible comprobar el apasionado enfrentamiento dialéctico y la Estereotipación de ambos grupos. En el primer número de El Editor Constitucional se presentó una caracterización de los "liberales" y los "serviles", cuyos términos definían "dos clases siempre en oposición», "como la luz y las tinieblas». El artículo contenía todas las características peyorativas insistentemente repetidas a lo largo del siglo por los liberales para definir a los conserva-

R. L. WOODWARD, "Grígenes económicos y sociales de los partidos políticos guatemaltecos (1773-1823)», Anuario de Estudios Centroamericanos, n. 1 (1974), pág. 74; J. LuJAN, "Los partidos politicos en Guatemala desde la Independencia hasta el fin de la Federación", Anales de la Academia de Geografía e Historia do Guatemala, n. 63 (1989), pág. 31. Ambos autores coinciden en señalar que a pesar de existir antecedentes, la situación política de 1820 , hizo posible el reconocimiento público de estos grupos.

8 Para el período de la Federación véase A. MARURf., Efemérides, hechos notables acaecidos en la república de Centroamérica desde el año 1821 hasta el de 1842, (1844), Guatemala, 1895; M. Garcia, Memorias del General Garcia Granados, (1877-93), Guatemala, 1952, 1. I; M. CoroNADO, Apuntes histórico-guatemalenses, Guatemala, 1987, págs. 47-166; J. C. PInTo, Centroamérica de la colonia al Estado nacional (1800-1840), Guatemala, 1989; M. WORTMAN, Government and Society in Central America, 1680-1840, New York, 1982; X. AvENDAÑo, "Procesos electorales y clase política en la Federación de Centroamérica (1810-1840)", tesis doctoral, Colegio de México, 1995; R. L. WoOdWard, Central America, a Nation Divided, Oxford University Press, 1985, págs. $92-148$.

9 A partir de 1842 los liberales que apoyaron al hondureño Francisco Morazán, para restablecer la unión de Centroamérica fueron designados "coquimbos" y a sus oponentes conservadores "cachurecos". En Nicaragua tradicionalmente los conservadores fueron reconocidos como "timbucos" y los liberales como "calandracas". 
dores y los historiadores liberales de finales de la centuria mantuvieron esta definición. Según dicho artículo, el conservador encarnaba los valores coloniales, la tiranía, la dominación despótica y la esclavitud. Su pensamiento contenía la negación del nuevo sistema político y de los principios que lo legitimaban y su acción estaba determinada por el interés particular 10. La crítica no estaba en la exposición de diferencias políticas, enmarcadas dentro de los principios constitucionales y republicanos, sino en que el conservador iba en contra de los mismos, "pues detesta las propias instituciones de la libertad". En cambio, "el liberal es el reverso de este cuadro", representaba la libertad, la tolerancia y la justicia y sus intereses y actuaciones se orientaban hacia el bien general ${ }^{11}$. A finales de siglo los liberales para defenderse de sus rivales políticos continuaron manteniendo los mismos argumentos. El partido conservador era «el defensor del pasado» y el partido liberal el "Campeón del porvenir»" 12 .

Los conservadores también generaron una imagen de los «fiebres" o «exaltados», con una réplica inversa a la estrategia liberal. Frente a lo que cabría pensar, de acuerdo a la versión tradicional liberal, los conservadores no negaban los valores y la legitimidad liberal. Muy al contrario, pretendían convertirse en los auténticos representantes de la libertad y de la democracia ${ }^{13}$, frente a las miras particularistas, la anarquía y el despotismo liberal ${ }^{14}$. Se denunciaba con insistencia el resultado de las políticas radicales aplicadas por los liberales durante la Federación. "A pretexto de establecer y sostener lo que se llamaba régimen liberal, se proscribia en masa a los pueblos, se perseguía a las clases útiles, se anulaban los estímulos del honor, se despedazaba la propiedad, y se

10 El Editor Constitucional, 24/VII/1820.

Ibid., 2 NIII/1820

12 P. BONiLlA, Colección de escritos, recogidos y ordenados por Emulo Duron, Tegucigalpa 1899, vol. I, pág. 34. En este mismo sentido, El Centro-americano, 3/XII/1881 publicado en A Rivas, Nicaragua. Su pasado, Ojeada retrospectiva, Managua, 1936.

13 El Tiempo, (Guatemala) 19/III/1839. La Asamblea de 1839, de mayoría conservadora, rectificó y derogó en gran parte las reformas liberales de los años anteriores, con el fin de lograr "una democracia efectiva y no una democracia de mampara detrás de la cual se agite y decida una oiigarquía tiránica y abusiva: nuestro Gobierno será popular y de consiguiente se hará lo que el pueblo quiera, y no lo que le repugne y deteste: tendréis un sistema de libertad, y por lo mismo, todo cuanto queráis para vuestra conciencia, para vuestra persona y vuestra propiedad, con tal que no ceda en daños de terceros".

14 El Mentor Costarricense, 25/III/1843; Gaceta Oficial de Nicaragua, 11/I1/1854 publicado en E. Álvarez, Las Constituciones de Nicaragua, Madrid, 1958; "Revista Politica sobre la historia de la Revolución de Nicaragua en Defensa de la Administración del Ex Director D. José Sandoval, Granada, 1847" en Revista del Pensamiento Centroamericano, n." 180 (julio-septiembre, 1983); "Habitantes de los Altos" (Guatemala), 1848, Collection 20, Central America Political Ephemera, Latin American Library, Tulane University (New Orleans, Louisiana), en adelante C20. 
oprimia a cuantos se suponía contrarios al desencantado sistema» ${ }^{15}$. La radicalidad, el fanatismo y la ceguera eran los calificativos que ponían de manifiesto la contradicción que afectaba a los liberales. En su intento de imponer cambios radicales y extraños en la sociedad llegaban a transgredir la voluntad popular, principio de legitimidad política fundamental ${ }^{16}$. Por el contrario eran ellos los que reconocian y actuaban de acuerdo a dicha voluntad. Identificándose con el pueblo manifestaban que «lo que él quiere es conforme con los principios de la verdadera libertad y en consonancia á los progresos del siglo presente. Quiere seguridad y justicia; no quiere el daño ni la opresión de nadie» ${ }^{17}$.

Junto al protagonismo de liberales y conservadores en la contienda política es preciso señalar la existencia de un grupo que, aún militando en estos partidos, no encontraron ubicación permanente por no lograr una identificación plena entre los extremos o las posturas más ortodoxas 18. Al margen del oportunismo político, personalidades como el general García Granados, en sus Memorias, iustificaron su afiliación al partido conservador a pesar de sus convicciones liberales. Tras la mención al partido liberal o fiebre formado por "hombres no sólo con ideas muy avanzadas y poco prácticas,... sino también anárquicas", confirma su afiliación al partido moderado o servil donde «figuraban liberales de buena fe, pero conservadores, que veian el peligro de procurar implantar en Guatemala las teorías más avanzadas de la Revolución Francesa... A este partido $s \in$ hallaban unidos los quietistas, ... los enemigos de las novedades y por consiguiente el clero y los más apegados al culto" ${ }^{19}$. La

\footnotetext{
15 El Tiempo, (Guatemala), 5/VII/1839. En este mismo sentido Gaceta Oficial de Guatemala, $17 / N / 1843$

16 La Gaceta, (Costa Rica), 13/NII/1850 publicado en J. Bernard. Pinceladas periodísticas de la Costa Rica del siglo xix por Adolphe Marie, 1816-1856, San José, 1976. Acusaciones que se prologan en toda la región hasta finales de siglo, E. GuzMAN, Huellas de su pensamiento, Granada, 1943 , págs. 274-275. En 1894 al criticar la "Libérrima" Constitución nicaragüerse de 1893 y a sus autores, se consideraba que "Jáctanse a cada rato los liberales en la Asamblea de sus ideas y sentimientos democráticos; pero sus actos prueban cuan poco hacen caso ellos de la voluntad popular".

17 El Tiempo, (Guatemala), 27/III/1839; Gaceta de Guatemala, 21/11/1850, "dieseamos como los que más, el orden y la libertad y una igualdad políticas bien entendidas. Alentaremos y aplaudiremos siempre cualquier adelanto: en nosotros no encontraran jamás obstáculo las mejoras". Véase también Gaceta de Guatemala, 11/VII/1851

$18 \mathrm{~J}$. L. ROMERo, El pensamiento conservador, Venezuela, 1978, pág. 19. El autor menciona la existencia de diferentes opciones dentro del pensamiento conservador que no se identificaron con las posturas más radicalizadas. C. MALAMUD, «Liberales y conservadores: Los partidos políticos argentinos (1880-1919)", Estudios Interdisciplinarios de América Latina y El Caribe (EIAL), n. 1 (Tel Aviv 1997), pág. 41. Estas diferencias también se dan en el grupo liberal, si bien la calificación y la delimitación de sus características presentan ciertos problemas.

${ }^{19}$ M. Garcia, Meinorias del General Miguel Garcia Granados, (1877), Guatemala, 1952, t. II, pág. 286.
} 
mención a los dos extremos no niega la existencia de otras propuestas y planteamientos, que se distinguieron por intentar el punto intermedio en el ritmo y la forma de generar la transformación precisa para construir una república de ciudadanos.

En las diferencias esgrimidas por unos y otros se buscaba la descalificación, situando al contrario frente a los valores que legitimaban el sistema político. Esta estereotipación se repite de forma idéntica en toda Centroamérica, incluso en Costa Rica donde generalmente se ha señalado la escasa rivalidad entre conservadores y liberales ${ }^{20}$. Los estereotipos polarizados de un partido y otro, más que reflejar sus concepciones políticas, revelan la importancia que poseía una nueva forma de legitimidad política. Es posible comprobar el grado de legitimidad de los principios representativos y liberales en la medida en que cada partido pretendía monopolizarlos y ser el único y verdadero representante de los mismos ${ }^{21}$. La profundización en el discurso de las diferentes opciones políticas sobre el proyecto de una república representativa y el significado de términos como libertad, igualdad, voluntad popular, república, participación popular, ciudadanía, etc., confirman la existencia de un proyecto común, más que la negación o la afirmación radical del mismo. Las caracteristicas comunes de los dos partidos muestran que la línea entre el liberalismo y el conservadurismo es "el criterio sobre cuál debe ser el ritmo que debe imprimirse a un proceso de cambio que ambas corrientes juzgan no sólo deseable, sino inscrito en las cosas mismas" 22 . Desde la Independencia, de hecho la tensión del debate no se dirimió entre su afirmación o su negación, sino en la forma que debía llevarse a cabo. "Todos los hombres que tenían influencia en los negocios convinieron unánimes en la necesidad de proclamarla... y solo había diferencias en cuanto a los modos de ejecución " ${ }^{23}$. De acuerdo al contexto de las concepciones políticas del siglo xix, la discusión se centró en la forma y las pautas en que debió llevarse a cabo la implantación de una

20 El Noticioso Universal, (Costa Rica), 7/VI/, 12/VII, 9/VIll y 1/XV/1834 en El Noticioso Universal, Enero de 1834 a Marzo de 1835, Academia de Geografía e Historia de Costa Rica, San José, 1987; El Mentor Costarricense, 15/Vl/1844

2: Esta estrategia de enfrentamiento está explicitada en El Noticioso Universal, (Costa Rica), 14/111/1834, págs. 598-599.

22 T. Halperin, "En busca de la especificidad del pensamiento político hispanoamericano», Estudios Interdisciplinarios de América Latina y El Caribe (EIAL), n. 1 (Tel Aviv), pág. 9.

23 A. Marure, Bosquejo histórico de las revoluciones de Centroamérica, desde 1811 hasta 1834, (1877-78), Paris, 1913, t. I págs. 12-13. Los entonces «imperiales" (conservadores) propusieron la anexión a México, bajo el Plan de Iguala del Emperador Iturbide, al considerar que un sistema monárquico constitucional garantizaría la moderación necesaria en "un asunto tan delicado". Por su parte, los «republicanos» (liberales) propusieron la declaración de Independencia, al margen de México, bajo un sistema republicano. 
nueva sociedad. En la discusión tanto de las reformas puntuales como de los proyectos a largo plazo, cada partido legitimó su planteamiento de acuerdo a un objetivo común. Este, según ambos partidos, consistía en implantar una sociedad compuesta de ciudadanos conscientes y formados que pudiesen expresar su voluntad, mediante elecciones regulares, para elegir gobiernos que se sometiesen al imperio de la ley.

El reto para lograr este proyecto, abordado bajo una concepción de cambio y transformación social diferente, radicó en la necesidad de "civilizar" a la "masa inculta» ${ }^{24}$. Una necesidad urgente y una preocupación permanente durante toda la centuria puesto que "hechos repetidos y manifiestos nos han convencido hasta la evidencia de que la ignorancia en la masa general del pueblo, es el obstáculo insuperable que impide el desarrollo de nuestros gérmenes de prosperidad" ${ }^{25}$. A finales de siglo la percepción del problema era el mismo y las necesidades también "Lo que ha menester... es que estas masas se instruyan, se eduquen, se civilicen i desfanaticen" ${ }^{26}$. La visión de una sociedad integrada por una parte consciente y civilizada y una mayoría embrutecida, incapaz por sí rnisma de tomar iniciativas coherentes, daba lugar a que el concepto de pueblo y participación popular fuera limitado. El pueblo considerado en el concepto mismo de República no sólo elegía sus gobiernos, sino también debía velar, como soberano, para que estos acataran la Constitución, sometiéndose al imperio de la ley ${ }^{27}$. Estas funciones implicabain que el pueblo tuviera que ver, leer, examinar y decidir ${ }^{28}$, requisitos en manos de un reducido número de personas, identificadas con parte ilustrada de la población. Cuando se utilizaba el término pueblo, de forma amplia y genérica, para considerar a los habitantes de la república, su sentido se modificaba y ya no aparecía como soberano sino como ignorante de sus derechos. "El pobre pueblo» no conocía la Constitución, desconocía las leyes que lo protegían y "no era amigo de novedades» ${ }^{29}$. Dentro de la ambivalencia y significados del término ${ }^{30}$, la concepcion limitada fue

24 El Redactor Oficial de Honduras, 30/V/1341; El Mentcr Costarricense, 25/III/1843.

25 «Excitativa hecha por el Gefe politico del Depertamento de S. Vicente al vecindario de la Ciudad del mismo nombre con el objeto de plantear la escuela Lancasteriana", (El Salvador), 27/IV $/ 1831$, C20.

26 El Porvenir de Nicaragua, 24/VIII/1878. En este caso Nicaragua no es una excepción sino un ejemplo que ilustra la percepción tanto de los liberales como de los conservadores centroamericanos.

27 La Oposición, (Guatemala), 13/1/1838.

28 "Contestación del Representante J. Barrundia al Jefe del Estado", (Guatemala), 11/VI/1837, C20, pág. 12; La Tribuna, 2/IX/1823.

29 El Semi-Diario de los Libres (Guatemala), 17/X1/1837; Gaceta del Gobierno Supremo del Estado del Salvador en la República de Centro-américa, 29/XIl/1848.

30 F. X. Guerra, Modernidad e Independencias, Madrid, 1992, págs. 351-381. 
la predominante. Ello explica las abundantes referencias hechas a las "masas" ignorantes movidas por el instinto y el impulso irracional ${ }^{31}$, para distinguirlas de la parte "sana" de la sociedad.

La aspiración de los liberales y de los conservadores fue hacer de sus repúblicas países civilizados que en el siglo $x \mid x, y$ podría decirse que en el $X X$, tuvo y tiene un sentido unívoco: el modelo occidental. Las "naciones civilizadas" gozaban de "instituciones libres, de paz y prosperidad" y en éstas "la reunión de los cuerpos legislativos era un acontecimiento notable»32. Frente a dichas naciones, la frustración permanente era la realidad que les circundaba debido a "la incompleta civilización de nuestros pueblos» ${ }^{33}$. El consenso no se limitaba a la percepción sobre su propia sociedad, sino que también ambos tenían la intención de transformarla siguiendo el ejemplo de los "pueblos cultos" y de los "paises privilegiados". Frente a aquella realidad, aspiraban a unna población uniformada y unida por la comunidad de ideas e intereses, y la civilización estendiendo su pacífico imperio hasta nuestros más remotos pueblos. He aquí un cuadro que todos, poco más o menos, hemos trazado en nuestro espíritu" ${ }^{34}$. Con una población uniformada y civilizada sería posible que fuera el pueblo quien rigiera y diese la ley ${ }^{35}$. El criterio básico para uniformar a la población serian los patrones culturales occidentales y entre los medios para lograrlo serían la educación y la inmigración de colonos europeos, tanto para los conservadores como para los liberales ${ }^{36}$. La asociación compartida de una república de ciudadanos conscientes y formados, con una sociedad homogeneizada bajo la cultura occidental queda en evidencia con el testimonio de los liberales salvadoreños al opinar que «ninguno de los Estados CentroAmericanos tiene contra sí tantos elementos de desorden y anarquía como Guatemala, por su población inculta y excesivamente heterojénea” ${ }^{37}$. EI

\footnotetext{
${ }^{31}$ El Mentor Costarricense, 25/III y 16/XI1/1843; "Revista Política sobre la historia de la Revolución de Nicaragua", pág. 33.

3. "Felicitación, que la municipalidad de esta capital dirijió a la Asamblea Constituyente del pue. blo libre y soberano de Guatemala», 18/VIII/1848, El Libro Verde, Latin American Library, Tulane University (New Orleans Louisiana), en adelante $L V$. Véase también, Gaceta de Guatemala, 14/XV/1851.

33 Gaceta de Honduras, 25/IV/1869; Gaceta de Guatemala, 14/IX/1848, "la mayoría de nues tra población se compone de indios enteramente ignorantes, otra gran parte de ladinos casi en el mismo estado y una fracción muy corta tiene algunas luces".

34 Gaceta de Guatemala, 21/ll/1850.

35 Ibid., 14/IX/1848, "Si es que queremos tener pueblo, en el sentido que lo toma Cicerón y los publicistas modernos, debemos darle todo el grado de civilización que es necesaria para que el rija y dé la ley".

${ }_{36}$ Los ejemplos desbordarían el espacio disponible. La educación y la inmigración fueron una preocupación permanente a lo largo de todo el siglo en Centroarnérica. $3 / X 1 / 1848$

37 Gaceta del Gobierno Supremo del Estado del Salvador en la República de Centro-América,
} 
hecho de que el resto de la región centroamericana contara con una población indígena menor no modificó su visión. La heterogeneidad étnico-cultural fue contemplada como un problema tanto para los liberales como para los conservadores de toda la región ${ }^{38}$. Por ello tanto en Guatemala, como en el resto de la región, a lo largo del siglo xIX, el concepto de república imperante determinó invariablemente que liberales y conservadores, aunque de diferente forma, pretendieran que dicha población abandonase su identidad, requisito imprescindible para lograr su ilustración o civilización ${ }^{39}$. La diferencia como venimos insistiendo radicaría en la forma de alcanzar este objetivo. Para los liberales un instrumento de homogeneización fundamental fue el ejercicio práctico de los derechos ciudadanos, pues la misma definición de ciudadanía contenía la exigencia de dejar de ser indio.

\section{EL CONCEPTO DE CAMBIO LIBERAL. LA REPÚBLICA AMPLIA EN LA CONSTITUCIÓN FEDERAL, 1824.1838}

A partir de la convicción común de que el pueblo debía aprender y asimilar una nueva concepción social ${ }^{40}$, la diferencia fundamental radicó en cómo alcanzar dicho objetivo. Los liberales creyeron que la puesta en práctica del mismo sistema republicano era la forma de alcanzar la meta propuesta. El carácter didáctico de sus instituciones a través de la participación de la población en las mismas, así como el ejercicio de los derechos civiles y políticos reconocidos en la categoría ciudadana sería el medio que garantizaría la transformación de la sociedad bajo los presupuestos de una república representativa. Para aleccionar al pueblo era necesario su participación «por-

\footnotetext{
38 "La heterogeneidad y la incultura" se consideraron un obstáculo para el establecimiento de instituciones republicanas en Centroamérica, "Discurso pronunciado por el Sr. Don José de Obaldía, en el salón del Palacio de Gobierno, el día 15 de septiembre de 1864, (Costa Rica), Alajuela, 1989. pág. 11.

39 Gaceta de Guatemala, 14/IX/1848, "llustremos a los indios si queremos que ellos no sean, como alguna vez han sido, el baluarte de la tirania: ilustrémoslos si es que deseamos afianzar las instituciones democráticas que hemos adoptado, porque ésta no puede existir si el mayor número no tiene participio en la cosa pública; ilustrémoslos no solo porque asi lo exije la humanidad y la justicia, que a todos nos considera con los mismos derechos, sino también por nuestra conveniencia, porque asi evitaremos la terrible guerra de castas de que nos vemos amenazados; ilustrémoslos, en fin, si deseamos ocupar en el mundo culto un lugar distinguido, y no aparecer a los ojos de las naciones civilizadas como unos bárbaros, indignos de estar al frente de los destinos del pueblo». En Costa Rica bajo el intento de "ilustrar" a esta población se fundó en 1831 un colegio para jóvenes indigenas, Ch. ZelayA, El Bachiller Osejo, San José, 1971, vol. II, págs. 56-62. Véase también "Exposición municipal sobre los sucesos de Costa Rica", 1//1831 en C. MELÉnDEZ, Documentos fundamentales del siglo xIX, San José, 1978, páy. 160; El Noticioso Universal, 4/X/1834.

${ }_{40}$ El Semi-Diario de los Libres, (Gluatemala), 17/XI/1837; "El pueblo de la capital de Guatemala á sus hermanos los demás pueblos de Centro-América", 23/VII/1838 C20.
} 
que no hay lección sin práctica; no hay vigor sin ejercicio. Las fuerzas naturales, como la inteligencia, como la moral, como la ciencia del gobierno, no se adquieren sino practicándolas". La implantación inmediata, y no progresiva, del sistema republicano proporcionaría un aprendizaje asegurado debido al efecto "saludable y moralizador" que, en si mismas, poseían las instituciones republicanas. Bajo esta concepción, en la lógica liberal, la transformación social sólo podía llevarse a cabo a través de los mismos cambios y de su vivencia: "¿Quién es, pues, el maestro de los pueblos independientes? Es la naturaleza sola, es la discusión pública, la imprenta libre y la revolución, y son los sacudimientos necesarios en los primeros pasos de un gobierno enérgico pero paternal y libre ${ }^{41}$. Las instituciones democráticas eran por tanto "escuelas», donde la participación proporcionaba un aprendizaje práctico, favoreciendo que "los ciudadanos más oscuros se eleven al desempeño de las mas augustas funciones» ${ }^{42}$. Bajo esta visión para los liberales el planteamiento conservador, basado en reformas lentas y progresivas, se traducía en la negación y resistencia al cambio que traía consigo la propia Independencia, asociada a la libertad y al progreso.

De acuerdo a esta concepción de transformación la república debía ser necesariamente amplia y participativa, pues mediante el ejercicio de los derechos civiles y políticos del ciudadano sería posible lograr la “ilustración» de las masas y con ello la construcción de una república civilizada. La confianza en la "magia" de las mismas instituciones republicanas y en la necesidad de ponerlas en prácticas como el medio mas seguro de aprendizaje determinó en buena parte que la Constitución Federal, primer texto constitucional centroamericano desde la Independencia ${ }^{43}$, estableciera una amplia definición de ciudadanía. Para

41 "Discurso de J. F. Barrundia. Independencia 15 de septiembre", sin fecha, citado en D. VELA, Barrundia ante el espejo de su tiempo, Guatemala, 1957, 1. II, pág. 46. En este mismo sentido se expresaban los liberales costarricenses El Noticioso Universal, 7/VI/1834.

4: El Album Republicano, (Guatemala), 11/XV/1848. Este articulo hace alusión a los beneficios que reportaba la participación de los ciudadanos en los juicios por jurados, establecidos en Guatemala bajo el gobierno liberal de Mariano Gálvez (1831-1838). Los juicios por jurado estaban contemplados en los Códigos de Livingston (Código penal y judicial de 1826 que se pensó para el estado de Louisiana pero nunca se implantaron en este estado). En Guatemala entraron en vigor en $1837 . \mathrm{M}$. Rodriguez, "The Livingston Codes in the Guatemalan Crisis of 1837-1838", en M. HaRRISON y R. WauchOPE (eds.), Applied Enlightenment: 19th Century Liberalism. New Orleans, 1972, págs. 1-32. Respecto a las reformas liberales en Guatemala en la década de los años treinta, D. BuSHNELL y N. MaCAUŁAY, El nacimiento de los paises latinoamericanos, Madrid, 1989, pág. 281, "excedian a cualquiera de las implantadas en aquella época en ningún otro lugar de la América Latina".

43 Las Constituciones de los estados integrantes de la Federación guardaron las mismas disposiciones que la Constitución Federal. Estas se encuentran publicadas en L. MARINAs Otero, Las Constituciones de Guatemala, Madrid, 1958 y Las Constituciones de Honduras; Madrid, 1962; R. GaLLARDO, Las Constituciones de El Salvador, Madrid, 1961, vol. II; E. Álvarez LeJARza, Las Constituciones de Nicaragua, Madrid, 1958 y G. H. Peralta, Las Constituciones de Costa Rica,Madrid, 1962. 
ser ciudadano era preciso estar casado o ser mayor de dieciocho años y tener una profesión "útil» o "medios conocidos de subsistencia". A la influencia del utilitarismo se suma la concepción de una ciudadanía basada en valoraciones morales confirmada en los casos de suspensión y exclusión, pues contemplaban la conducta notoriamente viciada y la incapacidad física o moral, judicialmente calificada ${ }^{44}$. La inexistencia de requisitos censitarios para ejercer los derechos políticos hizo posible que en la figura del ciudadano se concentraran derechos civiles y políticos. El ejercicio del voto por ia mayoría de la población, siguiendo la lógica del planteamiento liberal, era otro medio de aprendizaje que favorecería la formación de la ciudadanía. En cuanto a las personas que podian ser elegidas como representes de la Asamblea nacional y las estatales, así como para ser presidente de la república o para ser director de los estados miembros, las diferencias se limitaban a tener una edad superior a la del ciudadano.

La Constitución de Cádiz de 1812 fue un referente ideológico e histórico fundamental ${ }^{45}$. La Constitución Federal, vigente entre 1824 y 1838 , asumió la misma concepción de ciudadanía. Los casos de exclusión son idénticos y las connotaciones morales definían la idea de un ciudadano cuya forma de vida debía estar encauzada dentro de una recta moral. La condición de vecino como base definitoria de la ciudadanía en la Constitución gaditana fue asumida en Centroamérica durante buena parte del siglo $x \mid x{ }^{46}$ y su prolongada vigencia determinó, en gran parte, el modo en que se construyó la figura del ciudadano. En 1812 se alcanzó una síntesis entre nuevas y antiguas concepciones al agregar a la condición de vecino

44 Igualmente estaban excluidos los sirvientes domésticos, ver pág. Rosanvallón, Le sacre du citoyen. Histoire du suffrage universel en France. Francia, 1996, págs. 120-130, esta exclusión estaba justificada porque se consideraba que las personas en esta sifuación no tenian autonomia, ya que su depenciencia era directa. Estos se encontraban integrados en el cuerpo familiar y era el cabeza de familia quien !es representaba. Además de los motivos citados, la ciudadanía también se suspendia por haber cometido un delito cuya pena fuese más que correccional o por la condición de deudor.

45 Sobre la influencia de la Constitución de Cádiz, J. M. GARcía, Los origenes de la demo cracia en Centroamérica, Costa Rica, 1971; C. MElÉndez, La Independencia de Centroamérica, Madrid, 1993 y M. Rodriguez, El experimento de Cádiz en Centroamérica, 1808-1826, México, 1984, págs. 139 y ss. L. MARIÑas, Las Constituciones de Guatemala. páos. 67-69, afirma que a pesar de que los mismos autores de la Constitución federal dieron "la paternidad absoluta" a la Constitución norteamericana, los diputados centroamericanos «estaban mas versados en la técnica constitucional, las doctrinas y los principios proclamados en Cádiz".

46 Esta característica no se limita al caso centroamericano sino al Cono Sur y a México, D BUSNHELL, "El sufragio en la Argentina y en Colombia hasla 1853", Revista de Historia del Dere cho Ricardo Levene, $n$. 19 (1968) y M. CARMAgivanI y A. HERNANOEz, "La ciudadanía orgánica mexicana, 1850-1910", en $\mathrm{H}$. SABATO (coord.), Ciudadania política y formación de las Naciones. Perspectivas históricas de América Latina, Mexico, 1999, págs. 371-404. 
el principio igualitario de la ciudadanía. Tras eliminar todos los estatutos personales y colectivos vinculados a esta categoría, el ciudadano mantuvo las mismas cualidades que las del vecino, categoría básica en el Antiguo Régimen, tanto en España como en América Latina ${ }^{47}$. Dicha condición se encontraba intimamente ligada al espacio local, ya que la vinculación con la localidad era la característica más definitoria. Ello explica la necesaria adscripción del ciudadano a su comunidad, siendo además las autoridades locales quienes determinarían si reunía los requisitos precisos para serlo. Su moralidad, prestigio y contribuciones a la comunidad eran valorados subjetivamente en su seno. De esta forma, el concepto de ciudadanía se caracterizó por su carácter subjetivo y particular, basado en valoraciones morales y de prestigio, así como por su adscripción al ámbito local frente a una concepción objetiva y general ${ }^{48}$. De forma idéntica a la Constitución de Cádiz, la Federal también reprodujo el mismo sistema de elecciones. Partiendo de la unidad parroquial las elecciones se articulaban en tres grados más ${ }^{49}$.

\section{LA CIUDADANIA COMO UN MEDIO DE CIVILIZACIÓN. EL CASO DE LA POBLACIÓN INDÍGENA}

A pesar del carácter amplio y participativo del proyecto liberal, si atendemos a su finalidad éste no dejaba de ser limitado y excluyente. La finalidad perseguida era la de uniformar a la población bajo unos criterios establecidos unilateralmente por la elite. El caso de la población indígena, ciudadana y votante en la Constitución Federal es particularmente expresivo. La afirmación de la ciudadanía del indio era un medio inicial de homogeneización, que pretendia que el indio acabara por desaparecer. Su inclusión permitía afirmar que ya no existían indios sino ciudadanos. Aludiendo a la Constitución de Cádiz, los liberales afirmaban que ni la Constitución, ni los numerosos decretos de las Cortes diferenciaban entre el indio y el ciudadano. Si se pretendía que el indio dejara de serlo, el punto de partida era dejar de nombrarlo ${ }^{50}$. El proceso de civilización del indige-

\footnotetext{
47 F. X. GuerRa, «El soberano y su reino. Reflexiones sobre la génesis del ciudadano en América Latina", en H. SABAto (coord.), Ciudadanía politica y formación de las Naciones, pág. 47.

48 M. Carmagnani y A. Hernández, "La ciudadanía orgánica mexicana", págs. 385-386.

49 Los vecinos, en el primer nivel de voto, elegirían a los compromisarios de parroquia, éstos a los electores de partido y éstos a los de provincia.

so Ch. HALE, El liberalismo en la época de Mora, págs. 223-224. Según el autor hay un esfuerzo doctrinario por borrar la designación de «indio" de la vida mexicana. Para Mora por "ley ya
} 
na iba más allá de suprimirlo "por decreto" ${ }^{5 \dagger}$, más bien éste era el punto de partida de un proyecto de asimilación a través de la ciudadanía. Se trataba de que el indigena aprendiera y pusiera en práctica las cualidades que definian al ciudadano, ya que el ejercicio de la ciudadanía era un medio de civilización, a través del cual se lograría una república uniformada de ciudadanos ${ }^{52}$.

El perfil de la ciudadanía moral, expresado en la Constitución Federal, era la representación de las virtudes asociadas a la civilización occidental y la negación del estereotipo indígena. Si el indígena, a través del ejemplo de la población ladina (mestiza) y blanca, asumía los presupuestos exigidos para ser ciudadano acabaría por dejar de ser indio y se civilizaría. Con este objetivo fue incluido en la ciudadanía aunque en su definición estuviera implícita su exclusión. El hecho de que se entendiera la ciudadanía como un medio de civilización o asimilación de la población indígena hacía que su definición incluyera la contraposición de las caracteristicas que perfilaban la idea del indio. La embriaguez, por ejemplo, una de las características más definitorias ${ }^{53}$ y la degeneración moral que causaba ${ }^{54}$, negaba al indio los requisitos que debía reunir el ciudadano, padre de familia responsable, cuyo trabajo proporciona un medio "honesto de

no existian indios». A. Basave, México mestizo. Análisis del nacionalismo mexicano en torno a la mestizofilia de Andrés Molina Enriquez, México, 1992, pág. 23. "El lema de las clases privilegiadas de la época bien pudo haber sido... el de que un buen indio es un indio invisible». Respecto a la invisibilidad del indio véase $M$. CAsaus, "Los proyectos de integración social del indio y el ima* ginario nacional de las elites intelectuales guatemaltecas, siglos $\mathrm{x} \mid \mathrm{x}-\mathrm{x} \mathrm{x}$ ", Revista de Indias, 217 (Madrid 1999), págs. 775-813.

51 J. PIEL, Sajcabaja. Muerte y resurrección de un pueblo de Guatemala, 1500-1970. Guatemala-México, 1989, pág. 294.

52 De acuerdo a este planteamiento es de destacar la Constitución costarricense de 1844. A pesar de la iritroducción del sufragio censitario no se renuncia a la integración de los indigenas como ciudadanos y electores. Por ello se hace una referencia explícita a dicha población reconociendo su derecho al voto aunque carezca de las propiedades exigidas al resto de la población para poder votar. Esta Constitución estuvo en vigencia dos años.

53 E. BaAillas, El problema del indio durante el periodo liberal, Guatemala, 1989, págs. 2037. El autor describe con detalle los términos peyorativos que definieron at indio en el siglo $x / x$ Entre éstos estaba el de haragán, vicioso, obsceno, inconstante, traidor, ignorante, borracho... Sobre la permanencia de este estereotipo en el s. XX. M. CAsAus, Guatemala: linaje y racismo. Guatemala, 1992, págs. 221-231.

54 “Observaciones sobre chicha y aguardiente y su venta en puestos públicos, conocidos generalmente con el nombre de estanquillos", (Guatemala), 5/IV/1842, C20. pág. 5. "Todos los indígenas que entran y salen a diario de esta capital, así como el resto de los pueblos del Estado «siendo al mayor parte de indigenas. se mantiene en perpetua embriaguez... de la embriaguez diaria y continua, se siguen los homicidios, los asesinatos y heridas; las riñas; la prostitución y la liconcia; el abandono de los talleres; la disolución de los matrimonios y familias; las enfermedades consiguientes a la embriaguez, el odio y la impotencia para el trabajo». En Costa Rica la ociosidad la embriaguez, la rudeza y la violencia tambien definian al indigena, El Noticioso Universal, $5 / \mathrm{VI} / 1834$ 
vida", cualidades todas contrapuestas a la "incapacidad moral» del indio ${ }^{55}$. Por eso se pretendía que la práctica y el ejercicio de la ciudadanía les abriera "las puertas de la ilustración», al sacar "al humilde indio de la obscuridad $» 56$.

La instrumentalización de la ciudadanía se confirma con una legislación paralela que incluye los requisitos necesarios para ser ciudadano y que al mismo tiempo buscaba desarticular las señas de identidad indigena. A través de la generalización del castellano, la adopción de la indumentaria occidental, la extensión de la pequeña propiedad y la convivencia con el ladino y el blanco se pretendía convertir al indio en ladino y, por tanto, en un ciudadano responsable y consciente. En 1824, el Congreso Constituyente federal decretó el castellano como idioma nacional y la desaparición de las lenguas indigenas, recomendando que "aquellos que se llamaban ladinos se establezcan entre los indígenas con el fin de promover la extinción de sus lenguas nativas y su ilustración» 57 . El acceso del indio a una propiedad particular le proporcionaría un «modo honesto y conocido de vivir», “útil» al bien común, tal y como exigían las constituciones y la legislación electoral, hasta la década de los años setenta, como requisito para acceder a la ciudadanía. A esta finalidad parece orientarse la legislación de este período, que reducía a propiedad particular los terrenos baldíos ${ }^{58}$. A través de la generalización de la propiedad privada se pretendía extender una concepción individualista que colaborara a desarticular la comunidad y su sistema de propiedad. El concepto de república amplia, con la ciudadanía moral, se pensó como una forma práctica de aprender y entender los presupuestos básicos de la república representativa y lograr su consolidación. Para la población indígena implicaba civilizarse o, lo que era igual, occidentalizarse, pues una república solo podía serlo si estaba integrada por ciudadanos uniformados por la cultura occidental ${ }^{59}$.

\footnotetext{
55 El Tiempo, (Guatemala), 3/N/1839.

56 El Editor Constitucional, (Guatemala), 17/VIII/1820

57 M. PINEdA DE MONT, Recopilación de las leyes de Guatemala, Guatemala, 1869, 1. 1, lib. IV, tit. XII, ley n. 1; Archivo General de Centro América, A, B.119.3. Leg. 2538, Exp. 58475, 2/III/1825 y B.119.3, Leg. 2540, Exp. 58581, 27/IV/1836

58 Ibid., t. I, lib. IV, tit. VI, leyes n." 1-18; El Tiempo, (Guatemala), 30/VIII/1839. En la práctica la desamortización de tierras de la Iglesia y de terrenos baldíos favoreció la consolidación de los latifundios y el acceso a la tierra del ladino, en detrimento de las propiedades colectivas indigenas. Véase J. Castellanos (ed.), 500 años de lucha por la tierra, Guatemala, 1992, 2, vols.; D. Mcre ERY, "State Power, Indigenous Communities, and Land in Nineteenth-Century Guatemala, 1820 1920" en C. SMITH, Guatemalan indians and the State: 1540 to 1988, Texas, 1994, pags. 96-115.

59 B. Clavero, Derecho indigena y cultura constitucional en América, México, 1994, págs 20-28. En este sentido el autor afirma la existencia de "un vacio constitucional» ya que el indigena "debe abandonar sus costumbres y deshacerse de sus comunidades para conseguir integrarse en el único mundo constitucionalmente concebible del derecho".
} 
Hasta 1838, bajo la Constitución Federal fue posible mantener el proyecto de transformación liberal. Sin embargo tras su disolución y la constitución de las repúblicas en la década de los cuarenta los textos constitucionales expresaron una radical modificación de este proyecto. La participación política ciudadana dejó de ser un medio de civilización y se postergó como fin, configurándose un concepto restringido de república basada en un concepto de transformación lento y progresivo que no sólo será asumido por conservadores, sino por buena parte de los liberales centroamericanos, tras comprobar "las demasías de la representación popular» ${ }^{60}$.

\section{EL CONCEPTO DE CAMBIO CONSERVADOR Y EL NUEVO PLANTEAMIENTO LIBERAL. LA CIUDADANIA COMO FIN (1840-1870)}

Con la disolución de la Federación y la constitución de las repúblicas centroamericanas, se da por fracasado el proyecto de transformación liberal. Fara los conservadores la experiencia transcurrida desde la Independencia pone en evidencia dicho fracaso. La propuesta conservadora de moderación y tránsito progresivo era el único modo de «edificar algo sólido" en un futuro, según el movimiento social del siglo y las ideas de libertad y progreso ${ }^{61}$. La crítica a los «fiebres" sobre la forma de cambiar la sociedad se centró en el ritmo y los medios empleados para llevarlo a cabo. El fin pretendido por los liberales hasta la década de los treinta se realizó "sin medios adecuados» ${ }^{62}$. Sin embargo estas críticas también se hicieron por buena parte de los liberales, pues aún reconociéndose «entusiastas del progreso", aceptaban que "tristes y repetidos desengaños han venido... á demostrar prácticamente que los adelantos de la sociedad, son lentos, y que por querer apresurarlos imprudentemente, retrocedemos perdiendo lo adelantado" ${ }^{6}$. El predominio de un nuevo planteamiento sobre la forma y el ritmo necesario para lograr la construcción de una república equiparable a las de "las naciones civilizadas" tuvo una traducción inmediata en un modelo de república restrictiva y jerarquizada, que se plasmó en todos los textos constitucionales de la región.

60 f. MARURE, "Voto particular. Emitido por el que suscribe como individuo de la Comisión nombrada por el Supremo Gobierno para formar el proyecto de Ley Fundamental de la República", (Guatemala), LV.

61 Gaceta de Guatemala, 11/VII/1851

62 "Discurso pronunciado por el presidente de la Asamblea Constituyente don José M. Estrada" 1854 (Nicaragua), publicado en E. Álvarez, Las Constituciones de Nicaragua, pág. 114. $9 / 11 / 1849$ 
Bajo la perspectiva conservadora, el efecto didáctico de las instituciones republicanas foráneas había quedado invalidado debido a la reacción social y la inestabilidad política que habían provocado. El procedimiento liberal no sólo era ineficaz e ilusorio, sino también tiránico y contradictorio con los principios del sistema político que se pretendía implantar, pues se había hecho en contra de la misma voluntad popular ${ }^{64}$. El tránsito de súbditos a ciudadanos, sólo podía llevarse a cabo considerando las costumbres y el contexto particular ${ }^{65}$. El pueblo después de la anarquía y tiranía padecida por las políticas liberales estaba "curado ya por solemnes desengaños adquiridos en la escuela del dolor, ha comprendido que no se trasplantan de uno a otro pueblo las instituciones políticas, como no se trasplantan las peculiaridades que le sirven de fundamento; cansado ya de remolcar entre dos extremidades igualmente funestas (la colonia y la politica liberal), anhela un gobierno que en armonía con la situación y con las exigencias del siglo: libertad, igualdad, propiedad, seguridad, sea enérgico y vigoroso para obrar el bien; firme y recto para evitar el mal' ${ }^{66}$. Partiendo de este planteamiento, la transformación social debia ser gradual, adaptándola a la cultura o culturas de sus habitantes ${ }^{67}$, así como a su "grado de civilización" y formación política, que en las repúblicas centroamericanas se encontraba en «pañales» ${ }^{68}$. Esta opción no sólo aseguraba la consolidación de una nueva sociedad sino que evitaba la desestabilización social generada por la imposición de unas instituciones ajenas y extrañas

64 Gaceta de Guatemala, 9/II/1839. "Las constituciones, en efecto, nada valen, y son esteriles para la telicidad pública, siempre que se las considere como bastante eficaces y de trascendencia política, por solo ser una emanación impositiva del legislador. Creer que porque se reduce a escrito una opinión o principio teórico, haya de producir resultados prácticos, es creer en la magia de la varita de encantos, que a un sólo golpe hace producir espectros y fantasmas". Gaceta de Guatemala, 17/V/1843, "El empeño de introducir por la fuerza instituciones que no están enlazadas con las costumbres y opiniones de los habitantes de un pais, ha hecho muchas veces indispensables el empleo de la violencia, y de aqui ha provenido no sólo la ruina de las mismas instituciones, sino la de los gobiernos que se obstinan en plantearlas; y lo que es peor se aleja de gozar de las ventajas y beneficios que por su medio se aspiraba".

65 El Mentor Costarricense, 13/VII/1844.

66 "Discurso pronunciado por el presidente de la Asamblea Constituyente don José M. ${ }^{a}$ Estrada", 1854 (Nicaragua), pág. 113.

67 Gaceta de Guatemala, 21/1//1850. "Queremos que se respeten las creencias; que no se toque sino con mucho tiento, á las costumbres; que se hagan reformas en la sociedad, pero a la manera de las que se verificaban en la nave de Atenas, tabla por tabla, fragmento por fragmento; que nada se destruya sin contar primero con lo que se ha de sustituir; sin oponernos al espiritu mo. derno, comprendiéndolo como cualquiera y apreciando debidamente sus ventajas, rechazamos tan sólo sus excesos y rehusamos admitir lo que parece inaplicable, atendidos nuestro modo de ser particular y nuestras muy peculiares circunstancias "; En este mismo sentido, Gaceta de Honduras, 25/IV/1869.

68 "El pueblo de la Capital de Guatemala a sus hermanos los demás pueblos de CentroAmérica", 23/VII/1838 en C20; Gaceta de Guatemala, 31/V/1850 y $11 / \mathrm{VII} / 1851$. 
a las mismas costumbres ${ }^{69}$. Esta crítica era totalmente contraria a la concepción liberal, que justificaba la adaptación inmediata del sistema liberal debido a su carácter universal ya que "se presta a todas las situaciones y se combina con los pueblos más heterogéneos» 70 .

Por lo que respecta a los liberales, aunque se mantuvo un grupo que continuó sosteniendo el mismo proyecto de transformación, a partir de la década de los cuarenta, consideraron "preciso buscar otro camino", porque «en esa manía incorrejible que hemos adquirido de innovarlo todo cada año»... «inútilmente hemos pasado veintiocho años queriendo construir un edificio sin afianzar los cimientos" ${ }^{71}$. Tras esta renuncia la opción fue adoptar "el término medio" ${ }^{72}$, en el que primaria el desarrollo material, base fundamental para iniciar cambios progresivos adaptados a las costumbres, "sin negar los argumentos que pudieran hacerse, creemos que hai más graves razones para sostener lo ecsistente: razones sacadas, no de doctrinas jenerales de los publicistas sino de nuestro particular modo de ser, al cual es preciso, por decirlo así crearle una política peculiar» ${ }^{73}$. El rechazo a los extremos, «la antigua escolástica» y «la abstracción esteril» ${ }^{74}$, no implicaría la renuncia a los cambios. En la búsqueda del termino medio era preciso «experimentar con candor» ${ }^{75}$, siempre en armonía con las costumbres y el contexto particular.

En buena lógica con los nuevos planteamientos de transformación social, los textos constitucionaies centroamericanos bien fueran de autoría liberal o conservadora reflejaron un cambio respecto a la idea de república

69 «Revista Politica sobre la historia de la Revolución de Nicaragua», págs. 24-26; "Discurso pronunciado por el Sr. José de Obaldia", (Costa Rica), pág. 9.

70 La Tribuna. (Guatemala), 20/XI/1823; "El Generaí en jefe del ejército liberal, Máximo Jerez a los nicaragüenses" publicado en J. GAMEz, Biografia del General Máximo Jerez, (1882), Mana* gua, 1910

71 Gaceta del Gobierno Supremo del Estado del Salvador en la República de Centroamérica, $29 / \times 11 / 1848$.

72 Ibid., $i 6 / 11 / 1849$.

73 Ibid., 29 XII/1848.

74 "Discurso inaugural pronunciado ante la cámara legislativa de Costa Fica, por el presidente de la República, Dr. D. José M. ${ }^{\text {a }}$ Castro al tomar posesión del mando supremo el 8 de mayo de 1866" en C. MElendez, (comp.), Mensajes presidenciales, San José, 1981, pág. 49.

${ }^{75}$ "Discurso del Senador Moya, el 13 de marzo de 1845", (Costa Rica), publicado en Cl. Gonzalez VIQUez, El sutragio en Costa Rica ante la historia y la Legıslación, San José, 1978, pág. 209. "Discurso de D. Juan Lindo al inaugurarse la Asamblea Constituyente», (Honduras), 11 XI1/1847, en M. MEJIA, D. Juan Lindo. El Frente Nacional y el Anticolonialismo, Tegucigalpa, 1993, pág. 168, el presidente hondureño consideraba que cel espiritu de innovación y mejora es propio de nuestro siglo, y si han de procurarse para acercarnos a la perfección social porque todos anhelamos, es de apetecer que no permitáis ser arrastrados de sistemas brillantes, de ideas halagüeñas y seductoras, sin consultar nuestra capacidad y aptitud presente". 
amplia, como medio de civilización. Desde la década de los cuarenta se impuso un concepto de república restrictiva. La generalización de los derechos de ciudadanía y el ejercicio práctico de los mismos para favorecer la formación de la mayoría de los habitantes había resultado un fracaso. "La gran masa de la sociedad inculta e indiferente a los nuevos sistemas" no había aprendido y además había perdido hábitos de obediencia que no sólo habían desvirtuado el sistema representativo sino también favorecido el riesgo de una posible inversión social ${ }^{76}$. Este planteamiento no era una renuncia al proyecto común de civilización sino un cambio en la forma de llevarlo a cabo. Primero era preciso "ilustrar a las masas", incidiendo en los valores morales e inculcando el sentido de la responsabilidad y de la obligación, la educación y garantizando su subsistencia mediante el progreso material ${ }^{77}$. Construidas entonces las bases del "edificio social" sería posible aspirar al proyecto de república civilizada, en la que los ciudadanos tuvieran la capacidad de ejercer sus derechos libre y conscientemente.

Este proyecto de civilización se evidencia particularmente sobre la política dirigida a la población indígena. En Guatemala se decretó en 1839 el restablecimiento "del código de las leyes llamadas de indias, en todo aquello que no fuera contrario a la independencia y sistema de gobierno y se contraigan á la protección de los mismos indígenas" ${ }^{78}$. La justificación de esta medida era el fracaso del proyecto de civilización de los liberales ensayado durante la Federación: "La ilustración de aquellos no puede lograrse por el hecho de equipararlos legalmente á todos los demás asociados, como ya se ha visto antes de ahora; y lejos de eso, destruyéndoles ciertos hábitos de obediencia, quizás se les hace retrogradar á sus tiempos primitivos" ${ }^{79}$. Este

76 "Dictamen que la Comisión de Constitución dirigió a la Asamblea Constituyente al presentarle el proyecto de reformas que se le encomendó, 1844", (Costa Rica), en Cl. GonZALEZ, El SUfragio en Costa Rica, pág. 209; "Revista politica sobre la historia de la revolución en Nicaragua», págs. 25 y 64 .

Gaceta de Guatemala, 21/11/1850; "Inculcar el respeto a la autoridad constituida, la necesidad de trabajar para vivir y el deber de respetar lo ajeno, son los medios mas seguros, aunque lentos de civilizar a las masas ignorantes. Predicarles continuamente libertad, igualdad, soberanía... es conducirlas á la insurrección, es prestarles armas que se vuelven contra nosotros, haciendo prácticas y positivas las doctrinas que incautamente les hemos enseñado". En este sentido se expresaban los liberales haciendo especial incidencia en el desarrollo material, Gaceta del Gobierno Supremo del Estado del Salvador en la República de Centroamérica, 22/XI1/1848 y 16/1/1849; "Discurso inaugural pronunciado ante las cámara legislativa de Costa Rica, por el presidente de la República, Dr. D. Jose M. ${ }^{a}$ Castro al tomar posesión del mando supremo el 8 de mayo de 1866 ", pág. 47.

78 El Tiempo, 30/VIII/1839. Este decreto restableció la república de indios, forma de organización implantada en la colonia, S. ALDA, La participación indigena en la construcción de la república de Guatemala, s. xix, Madrid, 2000, págs. 37-61 y 213-220.

79 Gaceta de Guatemala, 17/ll/65. 
planteamiento no fue exclusivo de los conservadores guatemaltecos, los nicaragüenses se expresaron en términos idénticos ${ }^{80}$ y en las diferentes repúblicas centroamericanas se decretaron leyes particulares para la población indígena ${ }^{81}$. Incluso buena parte de los liberales centroamericanos, a pesar de disentir con el restablecimiento de la legislación colonial, reconocieron que quizás habían "errado al igualarlos" ya que "unas masas heterogéneas no deben gobernarse por unas mismas leyes" " 82 .

El decreto de 1839 pretendía una forma diferente de civilización, al tratar «no solo de protejer á esta clase numerosa de la sociedad, sino también fomentarla, mejorando las costumbres y civilización». La aplicación de una «igualdad mal entendida» «había dejado abandonada y desprotejida a una población falta de instrucción» ${ }^{83}$. Con la protección legal y la atención particularizada, siguiendo las Leyes de Indias, se pretendía impulsar un proceso de civilización coherente con el cambio progresivo y escalonado que definía la propuesta de los conservadores. Por otra parte, la recuperación de un estatuto particular proporcionaba la posibilidad de adaptar los cambios a la particularidad, en este caso, de la realidad indígena ${ }^{84}$. Este proceso de civiiización abandonaba la participación política como medio de civilización, pasando a ser el fin de la misma. Alcanzado el grado de instrucción suficiente, a través de inculcar el hábito al trabajo, la paternidad responsable, puniualidad, religiosidad y el aprendizaje del castellano ${ }^{85}$, la población indígena lograría la suficiente responsabilidad y conocimiento para ejercer derechos políticos. La finalidad, no obstante, era igual al proyecto liberal. Se trataba de dejar de ser indio, para integrarse en una república de ciudadanos occidentalizados. El planteamiento quedó definitivamente perfilado con la reducción del universo electoral en 1851 ,

so «Mensaje de S. E. El general director supremo don Fruto Chamorro a la Asamblea Constituyente del Estado de Nicaragua, instalada el 22 de enerc de 1854 " en E. Álvarez Las Consti tuciones de Nicaragua, pág. 109. "La heterogeneidad de la raza que se compone la población del Estado es un punto que merece llamar también vuestra alta mirada, porque la absoluta igualdad que entre una y otra se ha querido establecer refluye en perjuicio de la bienandanza social. La raza indigena más atrasada en todo que la otra, posee exclusivamente hábitos, preocupaciones y usos tan envejecidos que sólo el tiempo y la civilización pueden ir modificando: desterrarlos de golpe pudiera ser original de disturbios. . y por lo mismo la frudencia aconseja que para el réjimen de los indígenas haya instituciones excepcionales adecuadas a sus costumbres y carácter".

at C. Meléndez, La legislación indigenista de Costa Rica, México, 1957; E. Alvarado, La legislación indigenista de Honduras, México, 1958.

82 Gaceta del Gobierno Supremo del Estado del Salvador en la República de Centroamérica. $3 / X 1 / 1848$. Los propios liberales guatemaltecos se manifestaron en el mismo sentido. El Popular. $4 / X 1 / 1839$.

d3 El Tiempo, (Guatemala), 2/VII/1839

84 Ibid., 30/VIII/1839.

85 Gaceta de Guatemala, 17/1//1865 
adoptada como medida temporal hasta lograr el objetivo. En teoría y a pesar de la contradicción teórica y legal no parece que el estatuto indígena negara la ciudadanía a esta población sino que venía a agregarse a los derechos ciudadanos. Tampoco la ley de 1851 excluyó totalmente a la población indigena del electorado, pues al menos las autoridades municipales de las comunidades indígenas tuvieron derecho al voto.

\section{LA PRESERVACIÓN DE LA REPÚBLICA Y LA GARANTIÁA DE ELECCIONES LIBRES A TRAVÉS DE LA REPÚBLICA RESTRICTIVA}

El predominio de este planteamiento de transformación, tuvo su reflejo en todas las constituciones centroamericanas, sin excepción. La crítica vertida contra la «libertad exagerada», la profusión de garantías individuales, la concesión indiscriminada de la ciudadanía o la condena a la participación electoral de las masas ignorantes propiciada bajo la Constitución federal, no persiguieron la abolición del sistema representativo ni la negación de sus principios básicos. Muy al contrario el establecimiento de una república restrictiva tenía como objeto salvar el sistema republicano y no repetir "el gravísimo error» ${ }^{86}$ de la Constitución Federal. La razón de restringir la ciudadanía y/o la participación política era evitar la tiranía de "la democracia absoluta» tan funesta como la "monarquía absoluta» y preservar y garantizar los principios del sistema representativo ${ }^{87}$. El concepto de igualdad en este debate fue clave. Sin modificar la definición de igualdad de los "fiebres" se puso especial énfasis en la desigualdad de condiciones reconocida también por éstos ${ }^{88}$. La diferencia radicaba en que hasta el momento había sido "mal entendida" y aplicada, pues «la

B6 Ibid., 18/XII/1864. «Mensaje de S. E. El general director supremo don Fruto Chamorro a la Asamblea Constituyente del Estado de Nicaragua, instalada el 22 de enero de 1854", pág. 108; "Revista Política sobre la Historia de la Revolución en Nicaragua", pág. 72. El error había sido "la libertad de votos sin sisa ni escatima, sin ninguna condición de propiedad ni de ilustración, asi de los electores para ser admitidos en las Asambleas primarias electorales, como de los elegibles para ser colocados en los empleos; llamando a todo el Estado y abandonando a la clase más numerosa y menos ilustrada para el primero y principal acto del sistema electoral".

87 "Revista Politica sobre la Historia de la Revolución en Nicaragua», pág. 72 ; En referencia a Centroamérica en general, «Discurso pronunciado por el Sr. Don José de Obaldia», (Costa Rica), pág. 13.

${ }_{88}$ El Semi-Diario de los Libres, (Guatemala), 12/XV/1837, "Con respecto a la igualdad opinan los libres, que no es posible que la haya en talentos, en fortunas, en luces, ni en costumbres; y que no la hay de esta clase es un hecho; porque en una sociedad unos son muy hábiles, y otros muy rudos, unos sabios y otros ignorantes; porque hay ricos y pobres, virtuosos y malévolos"; E Noticioso Universal, (Costa Rica), 1//1834. 
igualdad social no consiste en hacer a todos ciudadanos y en conceder a todos los mismos derechos, preeminencias e inmunidades" ${ }^{89}$. La igualdad legal se había sustituido por la igualdad de condiciones, "barajando en confusa mezcolanza todas las desigualdades naturales... se había confundido el sabio con el ignorante, el juicio con el inquieto y el honrado ciudadano con el díscolo y perverso ${ }^{90}$. Esta perversión del principio de igualdad absoluta y de libertad exagerada era el principio de todos los males.

A partir de la década de los cuarenta se restringió el derecho al voto y/o el acceso a la ciudadanía mediante exigencias censitarias. Las exigencias morales heredadas de la Constitución de Cádiz se hicieron más explícitas, pues entre otros requisitos el ciudadano debía tener un «modo honesto de vida" "91. Los casos de exclusión fueron idénticos a los de la Constitución gaditana y federal e incluso se ampliaron por ser ebrio, jugador o truhán (Costa Rica: Constitución de 1847), por abandono de las obligaciones familiares o de la esposa sin causa legal (Costa Rica: Constituciones de 1841, 1844, 1859) o por el abandono del trabajo (Nicaragua: Constitución de 1854 y 1858). A estos requisitos para acceder a la ciudadanía se sumaron la exigencia de una propiedad o renta determinada o saber leer y escribir. En Nicaragua desde la Constitución de 1854 hasta la de 1893; en Honduras desde la Constitución de 1848 hasta la de 1865. En Costa Rica la Constitución de 1847 estableció que en cinco años para ser ciudadano era preciso saber leer y escribir y en la reforma de la misma en 1848 se establecía una renta o propiedad concreta y a partir de 1853 saber leer y escribir. Esta reforma estuvo en vigencia hasta 1859. En El Salvador desde la Constitución de 1841 la exigencia de leer y escribir o poseer una propiedad concreta para acceder a la ciudadanía también se introdujo en la defini-

\footnotetext{
89 "Mensaje de S. E. El general director supremo don Fruto Chamorro a la Asamblea Cons tituyente del Estado de Nicaragua, instalada el 22 de enero de 1854 ", pág. 108.

9o Este fragmento procede del "Discurso sobre la ciudadania" del mexicano Juan Mora y fue repetido insistentemente durante este periodo "Intorme de Isidro Menéndez". (EI Salvador), 1///1855 en N. Rodríguez, Historia de las Instituciones juridicas salvadoreños, San Salvador, 1951, pág. 240; "Revista Política sobre la Historia de la Revolución en Nicaragua”, pág. 72; "Discurso pronunciado por el Sr. Don José de Obaldia", (Costa Rica), pág. 73

${ }_{91}$ Las Constituciones centroamericanas del siglo xix y xx están publicadas en L. Mariñas Otero, Las Constituciones de Guatemala, y Las Constituciones de Honduras; R. GaLlardo, Las Constiuciones de El Salvador; E. Álvarez Lejarza, Las Constituciones de Nicaragua y G. H. PERALtA, Las Constituciones de Costa Rica. Véase también S. AldA, "El ciudadano y el voto. Estudio comparativo en Centrcamérica, 1824-1930" en R. SEvilla (coord.), Consolidación republicana en América Latina, Sevilla, 1999, págs. 17-33; A. Esgueva, Las leyes electorales en la Historia de NiCaragua, Managua, 1995; N. Chacon, Reseña de nuestras leyes electorales, San José, $1975 ; \mathrm{C}$. Araya, "Esbozo histórico de la institución del sufragio en Costa Rica", Avances de Investigación. n. 8 (San José 1983); M. Silva, "Desarrollo jurídico institucional del sistema electoral en Costa Rica, 1821-1870". Avances de Investigación, n. 5 (1990).
} 
ción de ciudadanía. Pero a diferencia del resto, en este caso fueron algunas de las condiciones exigidas, pues también el padre de familia o el cabeza de casa podían ser ciudadanos. En Guatemala, al igual que el resto de Centroamérica, permaneció el concepto de ciudadania moral, sin embargo no se agregaron exigencias censitarias que restringieran el acceso a esta categoría. A partir de la ley electoral de 1851 sin embargo se exigió para votar y ser elegidos requisitos censitarios, como en el resto de la región. Según, esta ley los electores, poseedores de una renta o propiedad concreta o por desempeñar algún cargo concejil, no sólo procederían de los departamentos sino también de los representantes de cinco corporaciones, la Universidad, el Cabildo eclesiástico, Corte de Justicia, el Consulado de Comercio y la Sociedad Económica ${ }^{92}$.

La restricción de ciudadanía, del electorado y de las personas elegibles no restó importancia a las elecciones y a su legitimidad. Liberales y conservadores a lo largo del siglo en su discurso defendieron que un gobierno sólo podía ser legítimo cuando recibia «su autoridad del sufrajio popular " ${ }^{93}$. Partiendo de este principio el establecimiento de una república restrictiva en cada república centroamericana se justificó por la intención de garantizar elecciones libres y auténticas. La participación electoral de las "masas", como medio de civilización y aprendizaje, había reducido las elecciones a una farsa. En coherencia con el concepto de cambio conservador y liberal moderado era necesario primeramente enseñar al pueblo y sólo entonces favorecer su participación política. "La diferencia estriba en que ellos (los liberales) juzgan que es útil y conveniente prolongar la ficción, y que el pueblo ha de aprender a fuerza de repetir el ejercicio mecánico de ir a votar con listas en que no sabe ni lo que va escrito, y nosotros buscando el mismo fin deseamos que se empiece por el principio: es decir, que los pueblos conozcan lo que es un diputado, un senador, un presidente, y las personas que son capaces de servir estos empleos, antes de hacer como que las nombran, y constituyen una representación que el público no reconoce ni respeta" ${ }^{94}$. La falta de "luces" para comprender el sistema electoral y el mismo significado del voto hacia que "las masas ignorantes" fueran víctimas de la demagogia y la manipulación y

92 Gaceta de Guatemala, 31/X/1851

93 "A los pueblos de Centroamérica". (Nicaragua) 23/VIll/1851, pág. 81 en A. VEGA BOLAÑos, Los acontecimientos de 1851. Notas y documentos. Managua, 1945; "Dictamen de la Comisión nombrada para presentar a la A. L. El cuadro demostrativo del número de Distritos electorales, del de electores que concurrieron y del de los candidatos que resultaron para la suprema Dirección de Nicaragua en 1853 y 1854 en A. VEGA, Gobernantes de Nicaragua. Managua, 1944, t. I, pág. 184; Gaceta de Guatemala, 16/VII/1852; El Mentor Costarricense, 22/IV y 20/V/1843.

94 Gaceta de Guatemala, 29/XII/1849. 
las elecciones una mentira ${ }^{95}$. Se consideró imprescindible modificar el universo electoral para asegurar votantes de criterio y "calidad" y no fueran así víctimas de la manipulación y el fraude con el fin de garantizar elecciones auténticas y ser gobernados por los "mejores ciudadanos". Para esto último además del voto consciente de la ciudadanía era preciso exigir a las personas elegibles condiciones superiores, en saber y propiedad a la de los propios electores y/o ciudadanos ${ }^{96}$. La cooperación entre el propietario y el hombre ilustrado garantizaban los principios del sistema representativo, la propiedad aseguraba la independencia e incorruptibilidad de los electores y de los elegidos, así como el interés por la conservación del sistema socio-político ${ }^{97}$.

En el caso de Nicaragua y Costa Rica además del sufragio censitario se estableció el sistema indirecto, como un medio más de neutralizar la ignorancia popular y la manipulación de las elecciones, ya que si con el sistema indirecto «las muchedumbres ignorantes pueden saber apenas qué ciudadanos en sus distritos, son aparentes para desempeñar las delicadas funciones de elector, sería pedirles un imposible (con el sistema directo) que supiesen cuáles otros ciudadanos en toda la república, son los más dignos de ocupar los elevados puestos de Presidente, Senadores i Representantes" ${ }^{98}$. En Costa Rica el sistema directo estuvo en vigencia entre 1844 y 1847. Además del voto directo, la Constitución de 1844 no imponía renta o propiedad alguna para acceder a la ciudadanía, si bien para votar establecía requisitos censitarios, menos para la población indígena. La Constitución de 1847 y la reforma de 1848, exigía saber leer y escribir en el plazo de cinco años para ser ciudadano, exigencias superiores para votar e implantó el sistema indirecto, derogando el sistema directo. Además de los inconvenientes

\footnotetext{
95 "Dictarren que la comisión de Constitución dirigió a la Asamblea Constituyente al presentarle el proyecto de reformas que se le encomendó", (Costa Rica), 1846 en J. SAENz CARBONELL, Los años del voto directo. D. Francisco Maria Oreamuno y la Constitución de 1844, San José. 1992, pág. 212; Gaceta de Guatemala, 1/XV/1850 y 19/IX/1851. En las elecciones "se aprovechan los demagogos y se ponen en juego las intrigas, para llevar como instrumentos a los individuos que pueden, sin saber estos lo que van a hacer, suplantándose votos, repitiéndose, y ha ciéndose otras varias cosas para llenar el número, de donde nunca puede obtenerse un resultado verdadero y útil»"

96 Gaceta de Guatemala. 12/VI/1848 y $16 / \mathrm{VII} / 1852$, "el cuerpo representativo de la nación, no será de hoy mas una reunión de hombres tomados á la casualidad y sin discernimiento, sin experiencia, ni respetabilidad, propios tan solo para obedecer ciegamente la voluntad del que los dirije a su placer. o para convertirse en instrumentos de oposición facciosa, ininteligible y desorganizadora". En este mismo sentido, M. PINEDA DE MONT, Recopilación de las leyes de Guatemala, $t$ I, tit. II, lib. II, nota 28

97 Revista Política sobre la Historia de la Fevolución en Nicaragua", pág. 33 y $72-74$; El Mentor costarricense, $15 / 11 / 1845$

98 "Discurso pronunciado por el Sr. Don José de Obaldia”, (Costa Rica), págs. 13-15.
} 
derivados de la organización que exigía el sistema directo ${ }^{99}$, "la ignorancia y la abyección del pueblo, la falta de virtudes cívicas..." obligaba a abolir un sistema de elecciones que "no es, no ha sido, no podrá ser muy pronto lo que se desea" ${ }^{100}$. De acuerdo al concepto predominante de cambio progresivo entre conservadores y liberales moderados, a partir de la década de los años cuarenta, estas modificaciones pretendían hacer una Constitución y un sistema electoral basado no en "teorías de una libertad exótica» sino adaptado a las costumbres del país. La adaptación a cada realidad particular no significaba aceptar el inmovilismo sino realizar progresos graduales y escalonados ${ }^{101}$. El sistema indirecto estuvo vigente en Nicáraguá hasta 1893 y en Costa Rica hasta 1913. En esta época los opositores al sistema de voto directo continuaron emplearon como principal argumento la manipulación del voto por la ignorancia popular ${ }^{102}$.

Desde la disolución de la Federación, en El Salvador, Honduras y Guatemala ${ }^{103}$, las elecciones fueron sin excepción directas, a lo largo del siglo. Los argumentos en estos casos no fueron muy diferentes, ni el objetivo tampoco. La legitimidad del sistema directo, como del indirecto en Nicaragua y Costa Rica, estuvo en pretender neutralizar la ignorancia de las masas para lograr unas elecciones "limpias y auténticas". En Guatemala, la campaña en contra del sistema de elección indirecto se basó en denunciar la irregularidad electoral e incluso las manifestaciones violentas y tumultos que éste favorecia ${ }^{104}$. Una vez aprobada la ley de 1838 , los im-

99 El Mentor Costarricense, 14/VI y 15/11//1845; "Discurso del Senador Moya", (Costa Rica), 13/11//1845. Los principales inconvenientes eran las numerosas convocatorias electorales corriendo el riesgo de "astiar al pueblo... distraido a cada rato de sus ocupaciones" haciendo las elecciones "al fin insoportables" o el tiempo al que se veía obligada la Asamblea legislativa en la apertura de pliegos y recuento de votos.

100 "Dictamen que la comisión de Constitución dirigió a la Asamblea Constituyente al presentarle el proyecto de reformas que se le encomendó", (Costa Rica), 1846 en Cl. GonzALEZ, El sufragio en Costa Rica, págs. 212-213.

101 Ibidem. En este mismo sentido "Reseña de la revolución de 1869", 19/1/1870 en A. RIVAS. Nicaragua. Su pasado. El programa de la revolución fallida de 1869, en Nicaragua, liderada por Máximo Jerez propuso el sufragio directo. Sin embargo se consideró que dicho programa invocaba teorías que exigian un alto grado de cultura, al que solo se podría llegar "con un trabajo asiduo... en la educación del pueblo".

102 O. Salazar, El apogeo de la república liberal en Costa Rica, 1870-1914, San José, 1990. pág. 134.

103 En Guatemala se estableció incluso antes de la disolución, “Ley reglamentaria de elecciones directas de diputados a la Asamblea Constituyente» del 9/VIII/1838 en Boletin Oficial, $n$. 129. (1838)

104 «Al público", 27/XIV/1837, LV; El Semi-Diario de los Libres, 3///1838; La Oposición, 4/l/1838; El Tiempo, $19 / / \mathrm{ll} / 1839$ y $6 / \mathrm{IV} / 1839$. Los artículos citados describen las maniobras de fraude y manipulación bajo este sistema. Las acusaciones en contra del sistema electoral y de sus manipuladores se dirigian al "partido ministerial» que reducía las elecciones a ejercicios nulos e ilegales. Según esto. las elecciones no eran mas que una farsa que atentaban contra el principio de soberanía popular. 
pulsores del voto directo consideraban que las elecciones "ya no presentaban ese triste cuadro", pues el nuevo sistema garantizaba "sin punto de ccmparación» la libertad electoral ${ }^{105}$. La adopción del sistema directo por las: leyes electorales siguientes parece demostrar la asociación generalizada entre el sistema electoral directo y la autenticidad democrática. El Acta Constitutiva de 1851 estableció un sistema de elección indirecto para el presidente de la república y para los magistrados de la Corte Superior de Justicia, a través del voto de los representantes de la Asamblea. El objetivo era poner fin a las intrigas y demagogia que la experiencia habia puesto de manifiesto, impidiendo hasta el momento que las elecciones fueran actos "verdaderos y útiles". Sin embargo el sistema directo se mantuvo para la elección de los representantes de la Asamblea legislativa, pues este mecanismo «más directamente popular era indispensable y necesario, pues no puede formarse, ni debe tener otro origen, la Cámara de Representantes» ${ }^{106}$. A pesar de las modificaciones sobre el sistema de elección del ejecutivo y del judicial no se cuestionó el sistema de elección directo para la elección de diputados. La argumentación básica que justificó la permanencia de elecciones indirectas, en Costa Rica, fue similar a la que utilizaron los impulsores del sistema directo en Guatemala. Más bien dependió de la legitimidad y autenticidad democrática con que se asoció un sistema u otro. En este sentido cabe destacar la legitimidad proporcionada por los valores representativos y las elecciones en toda la región. En ambos casos el argumento fundamental fue asegurar una auténtica democracia, basada en este período en la celebración periódica de elecciones, en las que debía primar la "calidad" de los electores y no su cantidad.

\section{LAS REVOLUCIONES LIBERALES, 1870-1900: EDUCACIÓN $Y$ TRABAJO MEDIOS PARA ALCANZAR UNA REPÚBLICA CIVILIZADA}

Entre 1871 y 1873 en todas las repúblicas centroamericanas a excepción de Nicaragua, tienen lugar episodios revolucionarios que garantizaron el acceso de los liberales al poder. A partir de entonces se inicia un segundo período del liberalismo que llega hasta $1945^{107}$. El retorno de los

105 El Tiempo, 6/IV/1839.

106 Gaceta de Guatemala, 19/IX/1851

107 A. TARACEnA, «Liberalismo y poder político en Centroamérica", (1870-1929) en V. H. Acuña, Historia General de Centroarnérica, Madrid, 1993, vol. IV, págs. 197-253. Para el autor este es un extenso período con diterentes etapas, a pesar de que tradicionalmente se ha considerado un proceso uniforme. 
liberales al poder en toda la región, en Nicaragua en 1893, estuvo marcado por la influencia ejercida por el positivismo. El positivismo centroamericano alcanza su apogeo y se convierte en «filosofía oficial» con el cambio de siglo, lo que significa no que no hubieran precedentes y un cambio de mentalidad desde mediados del siglo xIX y que a partir de la década de los setenta sea una referencia fundamental ${ }^{108}$. La importancia del desarrollo material y económico es uno de los elementos más característicos de esta nueva generación de liberales. Este objetivo no era nuevo, sin embargo a partir de la década de los setenta se desarrolla y se lleva a cabo de forma sistemática bajo la dirección del Estado. La construcción de infraestructuras favorecida por los ingresos que aporta la exportación del café se convierte en una de las prioridades estatales. El fomento de este producto no lo es menos. El cultivo del café se inicia con anterioridad, pero es en este período cuando adquiere mayor importancia, hasta el punto de convertirse en la base, junto con el banano, de la economía de agroexportación que permanece en la región hasta la actualidad.

El desarrolio económico trasciende más allá de los beneficios materiales que pudiera aportar, pues se convierte en el medio fundamental de transformación. El materialismo de los liberales responde a una concepción particular de cambio, cuyo objetivo es alcanzar la consolidación de una república civilizada integrada por ciudadanos formados e ilustrados. Este objetivo, perseguido desde principios de siglo, exigía renunciar a la política. Para que la "revolución lograra su verdadero fin" era preciso cambiar las prioridades, abandonar las discusiones que no tuvieran importancia "práctica» y «entrar con paso firme» en el terreno de los hechos y de las instituciones que puedan producir "la realización progresiva de los bienes sociales". Mediante reformas concretas y progresivas que potenciasen la agricultura, la industria, el comercio, las ciencias, las artes y la educación para a las masas ignorantes se crearían las bases necesarias para lograr "la verdadera República». En esta república sería entonces posible la implantación de las ideas propuestas por el partido histórico liberal. Por el momento no existían las condiciones sociales y políticas ${ }^{109}$. "Las lecciones del pasado" ya habían demostrado que los pueblos no se podían transformar en una "hora" y que no se podian "fabricar repúblicas admirables en un

108 R. L. WoOoWARD, «Pensamiento Cientifico y Desarrollo Económico en Centroamérica, 1860 1920", Revista del Pensamiento Centroamericano, n. ${ }^{\circ} 172-173$, (julio-diciembre, 1981), págs. 73-86.

109 R. Rosa, Obra Escogida, Tegucigalpa, 1980, págs. 143-147 y pp. 199-205. Ramón Rosa es considerado como uno de los principales intelectuales positivistas de la región. Formó parte del gobierno liberal hondureño de M. A. Soto (1876-1883), además de colaborar previamente en los gobiernos de M. Garcia Granados y J. R. Barrios en Guatemala desde 1871. 
día” ${ }^{110}$. El ritmo por tanto de las reformas propuestas debían estar adecuadas a las costumbres y a la realidad particular de cada república, tal y como se anunció por los primeros gobiernos liberales, a principios de los años setenta ${ }^{111}$. De acuerdo a esta concepción de cambio, la revolución liberal bajo la influencia del positivismo y su carácter práctico aceleró sin precedentes el desarrollo económico pero al mismo tiempo determinó que los liberales se integraran en los presupuestos del conservatismo del siglo $x x^{112}$.

Los puntos en común con el proceso de transformación defendido por los conservadores desde la década de los cuarenta, no significó que no hubiera diferencias reales y que entre sus señas de identidad no siguieran encontrándose la negación y crítica a los conservadores. Para esta nueva generación había un "abismo infranqueable" con la escuela conservadora que de hecho, obstaculizaba todo tipo de progreso y transformación. A diferencia de ésta el orden no era un fin supremo, sino un medio de realizar el derecho; no se irispiraban en la tradición y en el apoyo a la influencia eclesiástica, ellos aceptaban la libertad de conciencia; tampoco pretendía mantener perpetuamente la ignorancia de las masas, para dominarlas y manipularla, sino su instrucción de forma amplia y eficaz; negaban cualquier privilegio y pretendian la igualdad en el goce de los derechos; no apoyaban la estabilidad impidiendo la innovación; por el contrario protegían la iniciativa particular y pública, para favorecer el progreso ${ }^{113}$.

En este proceso progresivo de transformación mediante el desarrollo económico y material, la educación y el trabajo fueron piezas claves ${ }^{114}$. La importancia de la educación, fundamentalmente primaria, no era una preocupación nueva. Desde principios de siglo en toda la región se consideró imprescindible para la civilización u occidentalización de la población, ya que con ello sería posible la construcción de una república integrada por ciudadanos conscientes. Sin embargo bajo los regímenes liberales de este período la educación primaria se hizo obligatoria y gratuita y la inversión en educación no tenía precedentes, el ejemplo más exitoso en este sentido fue Costa Rica. Sin la instrucción, todo esfuerzo de transformación era en vano, pues únicamente mediante la formación de la población se

110 L. Montufar, «Discurso pronunciado en la Asamblea Constituyente», (Guatemala), $16 / X / 1876$, C. 20 , págs. 8-9.

111 "Lecciones al pueblo", (El Salvador), 15/1X/1871, C. 20; Boletín Oficial de Guatemala, $11 / \mathrm{VI} / 1871$ y 16/V/1872; El Guatemalteco, 23/VII/1876.

112 R. L. WoOdWARD, «Pensamiento Científico y Desarrollo Económico en Centroamérica 1860-1920". pág. 77.

113 R. Rosa, Obra Escogida, pág. 214.

114 Ibid., págs. 200, 202, 204 y 210. 
lograría el progreso y la construcción de una república uniformada por ciudadanos civilizados u occidentalizados. La educación, era "el bautismo de la civilización" y a partir de entonces el ciudadano sería capaz "de comprender claramente sus deberes, sus derechos, sus intereses, en una palabra capaz de conducirse i vivir bajo el imperio de la libertad» ${ }^{115}$.

En el caso de la población indígena su acceso a la ciudadanía, mediante la educación significaba renunciar a su propia identidad, objetivo último perseguido desde principios de siglo. En Guatemala, la profusa legislación orientada a garantizar la educación primaria así como la fundación de escuelas para indígenas se consideró el medio más seguro de civilización, ya que la instrucción garantizaría el abandono de sus costumbres ${ }^{116}$ y entonces "ese millón de parias, que hoy no forman parte de la república, serán en las generaciones próximas otros tantos ciudadanos" 117. A pesar de la continuidad de este planteamiento con el conservador, la república de indios y la legislación colonial no se consideró el medio idóneo de civilización. Retomando el planteamiento ilustrado, su mantenimiento perpetuaba la ignorancia y el atraso indigena, lo que equivalía a decir su identidad y los riesgos que ello suponía. "la historia nos demuestra que es harto peligroso dejar a los indios formar un status in statu, perpetuando su separación, la rusticidad de las costumbres, su miseria y todos los motivos de odio contra las castas" ${ }^{118}$. Frente al aislamiento se retomaron las propuestas de la convivencia del indio con el ladino, el aprendizaje del castellano y la utilización de la indumentaria ladina, junto con la insistencia en la instrucción primaria ${ }^{119}$. La extensión de la pequeña propiedad individual también fue un elemento "eminentemente civilizador» frente al sistema de propiedad comunitario ${ }^{120}$. La «fusión» con

115 El Guatemalteco, 11/XII/1875.

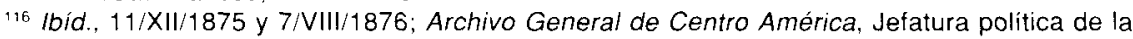
Alta Verapaz, 1872, "Informes sobre la implantación de escuelas en Cobán, Carchá y Tactic"; (Guatemala), Recopilación de las leyes emitidas por el gobierno democrático de la república de Guatemala, desde el 3 de junio de 1871 hasta el 30 de junio de 1881, Guatemala, 1881, t. II, decreto $241,6 / 1 X / 1879$, art. $2{ }^{\circ}$. "Se funda un colegio exclusivamente destinado a la civilización de los indijenas de la república". El Guatemalteco, 31/X/1878, en el discurso pronunciado en la instalación de la Escuela nocturna de indigenas de $\mathrm{S}$. Pedro las Huertas, se afirma que "civilizar al indio es... darles consistencia a estas efimeras democracias que no pueden vivir mucho tiempo teniendo en su seno el contrasentido de un pueblo de parias".

117 A. BATRES, Los indios, su historia y su civilización, Guatemala, 1894, pág. 200.

118 Ibid., pág. 2. La obsesión por la amenaza de una guerra de castas es permanente durante todo el siglo.

119 Ibid., págs. 184-191.

120 Ibid., pág. 172. "Muchos pueblos, numerosos de indigenas, que viven primitivamente, con sus sementeras, bosques, y prados en común, sin tener propiedad particular, ni darle importancia al individuo, sino solamente a la colectividad". 
la población ladina era la forma de desarticular a las comunidades, pues en su seno se reproducía y alimentaba la identidad indígena: «forman colectividades numerosas concentradas en sí mismas, sin expansión, sin roce con los demás pueblos: Todos los individuos de una misma parcialidad se visten del mismo modo, así como se vistieron sus antepasados hace miles de años; se casan entre ellos; alli se multiplican y extienden sin ningún elemento extraño; y viven y mueren, y van pasando de generación en generación» ${ }^{121}$. A principios del siglo $\mathrm{xx}$, la fusión de la población indígena con la población occidental ya no sería sólo una forma de diluir la identidad indígena sino también de mejorar la raza ${ }^{122}$.

En cuanto al trabajo, el otro pilar del progreso, se consideró imprescindible imponerlo a las clases más desfavorecidas como una forma de implicar a dicha población en los cambios del país, inmerso en el crecimiento agro-exportador. El contacto con la modernidad y los cambios aseguraría la deseada civilización ${ }^{123}$. El trabajo obligatorio, las leyes contra la ociosidad y la peonada por deuda pretendían asegurar la mano de obra precisa para el crecimiento econćmico. En Guatemala mediante el mandamiento, equiparable al repartimiento colonial, los indígenas fueron mano de obra necasaria para el crecimiento económico.

\section{LA EVOLUCIÓN DE LA REPÚBLICA A PARTIR DEL CIUDADANO ALFABETO}

Los presupuestos liberales generaron una modificación en los textos constitucionales respecio a la ciudadanía y al universo electoral, sin embargo estos cambios durante la década de los setenta no significaron la eliminación de límites a la participación política. A partir de la década de los ochenta se genera un nuevo cambio que según las repúblicas significará la evolución hacia el sufragio universal masculino como Honduras, El Salvador o Nicaragua o por el contrario hacia una república restrictiva como en Guatemala y Costa Rica a principios del siglo xx. A pesar de este cambio tanto en uno como en otro caso la educación fue el elemento más definitorio de la ciudadanía. El acceso de los liberales al poder de

121 lbid., pág. 197.

122 M. A. Asturias, "Sociología guatemalteca. El probierna social del indic», Tesis de graduación, U. S. C., Guatemala, 1923: Espinosa, El libro del ciudadano. Doctrinas juridicas contemporáneas, Guatemala, 1930.

123 S. P. PALMER, «A Liberal Discipline: Inventing Nations in Guatemala and Costa Rica», Tesis doctoral, Universidad de Columbia, 1990, págs. 271-284. 
forma prácticamente simultánea mediante revoluciones a partir de 1870 en la región, tiene su reflejo en las nuevas Constituciones aprobadas. Se eliminaron las exigencias censitarias y se conservó la figura del ciudadano moral, tanto en su definición como en los casos de exclusión. «El tener un modo de vida honesto" caracterizó la definición de ciudadanía en toda la región. Mediante esta definición de nuevo accedió a la categoría ciudadana la mayoría de la población ${ }^{124}$. En Costa Rica desde la Constitución de 1869 y de 1871, para ser ciudadano además de la edad, se requirió el poseer un "oficio honesto, para mantenerse con proporción a su estado". En Honduras esta definición entró en vigencia en la Constitución de 1865, al igual que la Constitución de 1873, texto surgido tras la revolución liberal que tuvo lugar en la república. Incluso en El Salvador, donde si bien la exigencia de una propiedad establecida por la ley fue una posible opción para acceder a la ciudadanía, a partir de su Constitución de 1871, ésta se sustituyó por poseer «un modo de vida independiente». La única excepción fue Nicaragua que mantuvo exigencias censitarias para acceder a la ciudadanía hasta 1893, además de morales. La ampliación de la ciudadanía, no significó que todos los ciudadanos votasen o que todos pudieran ser votados. De acuerdo al proceso de transformación progresivo y adaptado a las realidades particulares de cada república muchos liberales mantuvieron la defensa del voto censitario, aunque también había liberales más "radicales" que defendian el sufragio universal y el debate estaba ya presente ${ }^{125}$. Según las repúblicas se adoptaron diferentes formas para restringir la participación política durante la década de los setenta.

En Costa Rica, desde la Constitución de 1869 hasta la de 1917, se mantuvo el sufragio censitario y por tanto no todos los ciudadanos tuvieron derecho a votar, sin embargo la única diferencia entre electores y personas elegibles fue la edad. Por el contrario en El Salvador y Honduras, a lo largo de toda la década de los setenta, todos los ciudadanos tuvieron derecho a voto, pero no todos podían ser elegidos, ya que para ello era preciso poseer una propiedad concreta. En Guatemala, las leyes electorales desde 1871 hasta $1879^{126}$ mantuvieron el sufragio censitario y para ser

124 Diario de las sesiones de la Asamblea Constituyente de 1879. Reimpreso por acuerdo de la Comisión de régimen interior de la Asamblea Constituyente de 1927, Guatemala, 1927, pág. 85. "El modo honesto de vivir lo tiene el aldeano, lo tiene el artesano, to tiene el jornalero".

125 En este sentido es destacable la reproducción en La Gaceta de Honduras, 25/IV/1869, del debate a favor del sufragio universal en las Cortes Constituyentes españolas de 1868; El Boletin Oficial de Guatemala, 4/IV/1872; Véase también R. ROSA, Obra Escogida, pág. 214.

125 Este argumento justificó la restricción del electorado mediante las leyes del $11 / X 11 / 1871$ en el $B O, 24 / X \mid 1 / 1871$; ley del 21/X/1875 en El Guatemalteco, 12/XII/1875; la ley del $9 / X 1 / 1878$ en El Guatemalteco, 14/XII/1878. La continuidad de éstas con la de 1851 es evidente. La edad para 
elegido se exigió saber leer y escribir. La legitimidad de las diferentes formas de limitar la participación política fue la defensa del propio sistema representativo. La participación indiscriminada únicamente favorecía la manipulación de la masa ignorante y reducian las elecciones a una farsa, pues se la hacía partícipe de unos derechos que no entendía ${ }^{127}$. A través de la selección, mediante exigencias censitarias, de los electores o/y de los elegidos se pretendía una elección madura y consciente que asegurara el acceso a los cargos públicos de los "mejores», o en términos positivistas del "grupo científico" ${ }^{128}$. La fórmula adoptada fue una solución intermedia entre el modelo de república amplia de la Federación y de república restringida, configurada a partir de la década de los cuarenta bajo los conservadores y los liberales moderados. Durante la Federación, los derechos civiles y políticos se generalizaron a la mayoría de la población. Tras su disolución, los derechos civiles y/o políticos se restringieron a un sector de la población y además se mantuvo una jerarquía interna, pues no todos los electores podían ser elegidos. A diferencia de los periodos anteriores durante la década de los setenta, podría afirmarse que, en términos generales, la mayoría de la población disfrutó de los derechos civiles pero no políticos.

A partir de 1880 hay un cambio fundamental, cuya evolución marca importantes diferencias dentro de la región. En Honduras y El Salvador y en Nicaragua, a partir de 1893, se consolidó un concepto amplio de república, respecto al período anterior. Manteniéndose la definición de ciudadanía establecida desde los años setenta, no consta restricción alguna que impida que todos los ciudadanos pudiesen votar. En cuanto a las personas elegibles sólo se diferencian de los ciudadanos por la exigencia de una edad superior. De esta forma aunque no se establece en sentido estricto el sufragio universal masculino, si puede afirmarse el establecimiento de un concepto de república amplia y más igualitaria, pues el ciudadano y el elector coinciden y las personas elegibles únicamente se diferencian por la edad. Este concepto de república se mantuvo hasta finales del siglo XIX, límite temporal del presente trabajo. En Nicaragua, la Constitución de 1893 estableció las mismas características y condiciones

tener derecho al voto descendió, pero el electorado continuó restringido a un grupo concreto de ciudadanos debido a la exigencia de poseer una renta concreta o saber leer y escribir para tener derecho al voto. Igualmente, los artesarios y las personas que ostentaran cargos concejiles continuarían siendo electores. No obstante, habia diferencias pues desapareció la representación corporativa.

127 "Administración provisoria del C. Jeneral Miguel García Granados", (Guatemala), 20/VII/1872, C20 y E! Malacate, (Guatemala), 23/VIII/1871

${ }_{128}$ “Lecciones al pueblo", (El Salvador), 15/1※/1871, C.20, pág. 37. 
que en El Salvador y Honduras. A partír del período señalado es posible comprobar también que progresivamente, a lo largó de la década de los noventa, las connotaciones morales fueron desapareciendo. La definición de ciudadania únicamente se basó en exigir una edad determinada, que descendía para aquellas personas que fueran alfabetos o poseyeran título literario. En los casos de exclusión también fueron desapareciendo las connotaciones morales. Sin embargo no se eliminó la vagancia. Posiblemente el mantenimiento de este caso de exclusión se deba a la importancia y al significado concreto otorgado al trabajo, bajo la influencia del positivismo. El caso de Guatemala puede aportar en parte una posible explicación al carácter amplio y participativo experimentado en el concepto de república a partir de los años ochenta. La Constitución de 1879 generalizó la ciudadanía y el derecho al voto e incluso, a diferencia de otras repúblicas, tampoco exigió una edad superior para poder ser elegido. Sin embargo, no significó la renuncia a los principios de transformación asumidos a partir de las revoluciones liberales de la década de los setenta. Las similitudes con la república amplia establecida durante la Federación no suponía aceptar el ritmo y la forma de transformación social y política de los liberales centroamericanos de la primera generación. Los liberales positivistas en la década de los ochenta no creyeron en la "magia de las Constituciones", sino más bien en la "magia" de la educación ${ }^{129}$. De acuerdo con la importancia otorgada a la educación en los presupuestos positivistas se consideró viable la generalización de la ciudadanía y el voto pues "con el transcurso del tiempo destruiría por sí sola y matemáticamente, los inconvenientes que se desprenden de esa latitud" ${ }^{130}$. No es por casualidad que en esta misma época la educación primaria se hiciera obligatoria y así lo contempla la misma Constitución de 1879, como ocurre en el resto de la región.

Costa Rica presenta una evolución diferente de carácter restrictivo, después de la Constitución de 1871 no se introdujo ninguna modificación que ampliara el universo electoral como en el resto de las repúblicas en la década de los ochenta o noventa. De esta forma a pesar de la ampliación de los derechos civiles a la mayoria de la población, el derecho al voto se mantuvo restringido a los ciudadanos que fueran alfabetos y tuvieran una renta concreta. La reforma constitucional de 1917, eliminó la figura de

129 El Guatemalteco, 11/XII/1875. "la influencia de la instrucción es maravillosa; lo modifica todo como por encanto".

130 “Preámbulo del ex representante Rafael Montúfar» en el Diario de las sesiones de la Asamblea Constituyente de 1879 reimpreso por el acuerdo de la comisión de régimen interior de la Asamblea Constituyente de 1927, pág. 12. 
elector, pero en la misma reforma se contemplaba que a partir de 1927 se exigiría saber leer y escribir para acceder a la ciudadanía, o poseer una renta o propiedad concreta. En cuanto a las personas elegibles no sólo debía tener una edad superior a la de los ciudadanos sino poseer una renta o capital concreto. Sin embargo Costa Rica no fue una excepción. En Guatemala si bien hasta finales del siglo XIX presentó una evolución similar a El Salvador, Honduras y Nicaragua, la Constitución de 1921 restringió el acceso a la ciudadanía a los alfabetos y a las personas que desempeñaran o hubieran desempeñado cargos municipales. Los principales motivos de esta restricción se debieron al fracaso en la alfabetización de la población. En este caso mientras que en resto de la región la educación fue una exigencia que favoreció una mayor participación, al proporcionar la calidad de ciudadanos a las personas con menor edad que fueran alfabetos. En Guatemala y en Costa Rica a principios del siglo $x x$ fueron una forma de exclusión.

\section{CONCLUSIÓN}

Los diferentes temas suscitados como objeto de discusión durante buena parte del siglo $x i x$ tuvieron como trasfondo la forma en que debía construirse una república representativa integrada por ciudadanos conscientes y formados, bajo los patrones culturales occidentaies. En este debate, tanto los liberales como los conservadores legitimaron todo proyecto y acción política de acuerdo a los valores republicanos y a los deseos de la voluntad popular, dentro del contexto de las ideas y valores propios de la época. Frente a la versión generalizada, ni los liberales pretendieron alcanzar una democracia universal, ni los conservadores negaron sistemáticamente los valores y concepciones politicas que modificaban la sociedad colonial. Las diferencias se basaron en las distintas formas de transformación para lograr la realización de dicho proyecto. La forma y los medios con los que se identificó cada partido fueron los puntos básicos de desencuentro. Bajo esta discusión puede entenderse la mayoria de las diferencias que los separaron en temas concretos. De acuerdo a éstos, los liberales y los conservadores asignaron distintas funciones a la iglesia, la religión, a la ciudadanía o a las elecciones. Incluso, de acuerdo a la forma en que entendieron la transformación hacia una sociedad liberal se dibujaron repúblicas muy distintas.

En coherencia con el proceso de transformación de los liberales y los conservadores es posible comprobar un reflejo inmediato en la definición de ciudadanía y en el universo electoral, delineando la evolución 
que presenta el concepto de república a lo largo del siglo xIX en la región centroamericana ${ }^{131}$. El carácter didáctico de las instituciones republicanas a través de la participación de los ciudadanos en las mismas, así como el ejercicio de los derechos reconocidos por dicha categoría legal fue la forma en que los liberales vieron la posibilidad de trasformar la sociedad bajo los presupuestos de una república representativa. De acuerdo a esta concepción de transformación, la Constitución Federal, vigente entre 1824 y 1838 , estableció una república amplia, ya que si la mayoría de la población accedía y ponía en práctica los derechos civiles y políticos reconocidos en esta categoría se aseguraría su aprendizaje. Con la disolución de la Federación esta forma de transformación se consideró fracasada. Los conservadores y los liberales moderados concibieron este cambio bajo pautas moderadas y progresivas y adaptadas a la realidad de cada república, pues sólo así se lograría consolidar los principios de una república representativa. Bajo este presupuesto de transformación se estableció una república restrictiva, que según las repúblicas y las Constituciones limitó incluso el acceso a la ciudadanía mediante exigencias censitarias. El resto de la población, inmersa en la ignorancia debía adquirir un aprendizaje previo. Según fueran liberales moderados o conservadores los criterios de esta formación variaban pero el planteamiento era similar.

La última fase diferenciada ha sido las revoluciones liberales, que casi simultáneamente se dan en la región a principios de la década de los setenta, a excepción de Nicaragua. Bajo la progresiva influencia del positivismo, en este período se pretendió establecer un punto intermedio en los medios y forma de transformar la sociedad. Su acción se concentraría en el crecimiento económico y material de la sociedad y a partir de esta base sería posible iniciar la construcción de una república. Los medios básicos de transformación serían la educación y el trabajo. Su confianza en la capacidad transformadora de la educación haria posible introducir progresivamente cambios, y convertir a la mayoria de la población en ciudadanos. En coherencia con estos presupuestos, las Constituciones centroamericanas ampliaron la definición de ciudadanía, aunque se limitó la participación política. En la década de los ochenta en las Constituciones de El Salvador, Honduras, Guatemala y Nicaragua las exigencias censitarias desaparecieron tanto

131 M. QuIJADA, «QQué Nación? Dinámicas y dicotomías de la Nación en el imaginario hispanoamericano del siglo XIX" en M. QuIJADA y F. X. Guerra (coords.), "Imaginar la Nación", $A H I L A$, n. 2 (1994), págs. 49-77. Siguiendo la evolución de la ciudadania y el proyecto de homogeneización pretendido en Centroamérica es posible distinguir los distintos modelos de Nación que fueron configurándose a lo largo del siglo xix en América Latina, pasando de la Nación civica a la Nación, distinguidos por la autora, que fueron configurándose a lo largo del s. xIx en América Latina. 
para votar como para ser elegido, éstos últimos debian tener una edad superior a la de los ciudadanos. La fe en la educación fue unos de los factores que favoreció la consolidación de una república amplia, ya que la formación proporcionada por la educación primaria obligatoria iría eliminando «los riesgos» implícitos en la participación política de las «masas». En el caso de Costa Rica su evolución fue restrictiva. La Constitución de 1917 confirma esta evolución, en la que en el término de diez años se exigiría a los ciudadanos ser alfabetos. Guatemala, adoptó características similares. Tras establecer una república amplia desde la Constitución de 1879, la Constitución de 1921 exigió saber leer y escribir para ser ciudadano. Ante el fracaso de generalizar la educación se optó por restringir la ciudadanía a aquellas personas que supieran leer y escribir. En este proceso de evolución cabe destacar la influencia de la Constitución de Cádiz de 1812. La definición de ciudadanía de esta Constitución se mantuvo a lo largo del siglo. La introducción de exigencias censitarias se agregaron al perfil del ciudadano moral establecido desde la mencionada Constitución.

Por encima de las diferencias, para unos y otros una condición fundamentai para construir dicha república era "civilizar" a las masas. La evolución de la ciudadanía dependió de las distintas formas en que se entendió el modo de llevar dicha civilización. En el caso de la población indígena la ciudadaría implicaba dejar de ser indio. En Guatemala, cuando se pensó que el ejercicio de la ciudadanía no había logrado su objetivo, los conservadores, en 1839, situaron nuevamente en minoría de edad a la población indígena, con el fin de inculcarla progresivamente los hábitos y costumbres occidentales. En 1871, retomando el planteamiento de asimilación ilustrado, como hiciera la primera generación de liberales, se pretendió la homogeneización cultural de la república con el fin de lograr el progreso y modernización del país. El contacto con la población ladina y la extensión de la instrucción primaria serían los medios fundamentales de civilización.

\section{BIBLIOGRAFIA}

ALDA, Sonia: “El ciudadano y el voto. Estudio comparativo en Centroamérica, 1824-1930" en R. SEVILLA (coord.), Consolidación republicana en América Latina. Sevilla, 1999.

ALDA, Sonia: La participación indigena en la construcción de la república de Guatemala, s. xIx, Madrid, 2000

Alvarado, Ernesto: La legisiación indigenista de Honduras. México, 1958.

Álvarez Lejarza, Emilio: Las Constituciones de Nicaragua, Madrid, 1958.

Araya Pochet, Carlos: "Esbozo histórico de la institución del sufragio en Costa Rica", Avances de Investigación, n. 8 (San José 1983)

ARGUETA, Mario: La primera generación liberal: fallas y aciertos (1826-1842), Tegucigalpa, 1999. ARtola, Miguel: "La Monarquía parlamentaria", M. ARTOI.A (ed.), "Las Cortes de Cádiz", Ayer, ก. ${ }^{\circ}$ (Madrid, 1991). 
Asturias, Miguel A.: "Sociología guatemalteca. El problema social del indio", Tesis de graduación, U. S. C., Guatemala, 1923.

Avendaño, Xiomara: "Procesos electorales y clase política en la Federación de Centroamérica (1810-1840)", tesis doctoral, Colegio de México, 1995.

BANCROFt, Hubert H.: History of Central America, San Francisco, 1886-87

BARILLAS, Edgar: El problema del indio durante el período liberal, Guatemala, 1989.

Basave Benitez, Agustín: México mestizo. Análisis del nacionalismo mexicano en torno a la mestizofilia de Andrés Molina Enriquez, México, 1992.

Batres, Antonio: La América Central ante la Historia, (1915-1949), Guatemala, 1949.

BATRES, Antonio: Los indios, su historia y su civilización, Guatemala, 1894.

Bernata VIllar, Jeannette: Pinceladas periodisticas de la Costa Rica del siglo xix por Adolphe Marie, 1816-1856, San José, 1976.

BONILLA, Policarpo: Colección de escritos, recogidos y ordenados por Emulo Duron, Tegucigalpa, 1899.

BUSNHELL, David: "El sufragio en la Argentina y en Colombia hasta 1853", Revista de Historia del Derecho. Ricardo Levene, n. 19 (1968).

BuShnelL, David, y MACAULAY, N.: El nacimiento de los paises latinoamericanos, Madrid, 1989.

Carmagnani, Marcelo y Hernandez, Alicia: "La ciudadanía orgánica mexicana, 1850-1910", en H. Sabato (coord.), Ciudadanía política y formación de las Naciones. Perspectivas históricas de América Latina, México, 1999.

CASAuS ARzU, Marta: Guatemala: linaje y racismo, Guatemala, 1992

CASAUS ARzU, Marta: "Los proyectos de integración social del indio y el imaginario nacional de las elites intelectuales guatemaltecas, siglos XIX-XX", Revista de Indias, 217 (Madrid 1999).

Castellanos, Julio: Café y campesinos en Guatemala, 15.38-1879, Guatemala, 1987.

CHACon, Nelson: Reseña de nuestras leyes electorales, San José, 1975.

Clavero. Bartolome: Derecho indigena y cultura constitucional en América, México, 1994.

Coronado Aguil.ar, Manuel: Apuntes histórico-guatemalenses, Guatemala, 1975.

Diario de las sesiones de la Asamblea Constituyente de 1879. Reimpreso por acuerdo de la Comisión de régimen interior de la Asamblea Constituyente de 1927, Guatemala, 1927.

- "Discurso pronunciado por el Sr. Don José de Obaldía, en el salón del Palacio de Gobierno, el día 15 de septiembre de 1864". Alajuela, 1989.

- El Noticioso Universal, Enero de 1834 a Marzo de 1835, Academia de Geografia e Historia de Costa Rica, San José, 1987

Esqueva, Antonio: Las leyes electorales en la Historia de Nicaragua, Managua, 1995.

ESPINOSA, Horacio: El libro del ciudadano. Doctrinas juridicas contemporáneas, Guatemala, 1930.

GallaRdo, Ricardo, Las Constituciones de El Salvador, Madrid, 1961, 2 vols.

Garcia Granados, Miguel: Memorias del General Miguel Garcia Granados, (1877), Guatemala, 1952, t. II.

Garcia Laguardia, Jorge M.: Los origenes de la democracia en Centroamérica, Costa Rica, 1971.

GonzÁlez VIOUEZ, Cleto: El sufragio en Costa Rica ante la historia y la Legislación, San José, 1978.

Gudmundsun, Lovell: "Sociedad y política (1840-1871)", en H. Pérez (ed.), Historia General de Centroamérica, Madrid, 1993, t. III.

GuerRA, François- Xavier: Modernidad e Independencias, Madrid, 1992.

GuERRA, François-Xavier: "The Spanish-American Tradition of Representation and its European Roots", Journal of Latin American Studies, n."1 (1994).

GuerRA, François-Xavier: «El soberano y su reino. Reflexiones sobre la génesis del ciudadano en América Latina", en H. SABATO (coord.), Ciudadanía política y formación de las Naciones. Perspectivas históricas de América Latina, México, 1999.

GuZMÁN, Enrique: Huellas de su pensamiento, Granada, 1943.

Hale, Charles: El Liberalismo mexicano en la época de Mora, 1821-1853, México, 1977.

HALPERIN DONGHI, Tulio: "En busca de la especificidad del pensamiento politico hispanoamericano", Estudios Interdisciplinarios de América Latina y El Caribe (EIAL), n. ${ }^{\circ}$ (Tel Aviv 1997).

LUJAN MUÑOZ, Jorge: "Los partidos políticos en Guatemala desde la Independencia hasta el fin de la Federación", Anales de la Academia de Geografia e Historia de Guatemala, n. 63 (1989) 
Malamud RIKLES, Carlos: «Liberales y conservadores: Los partidos políticos argentinos (18801919)", Estudios Interdisciplinarios de América Latina y El Caribe (EIAL), n. ${ }^{\circ}$ (Tel Aviv 1997).

MARINAS Otero, Luis: Las Constituciones de Guatemala, Madrid, 1958

- Las Constituciones de Honduras, Madrid, 1962.

Marroquin Rojas, Clemente: Morazan y Carrera, Guatemala, 1965;

MaruRE, Alejandro: Bosquejo histórico de las revoluciones de Centroamérica, desde 1811 hasta 1834, (1877-78), Paris, 1913.

MARURE, Alejandro: Efemérides, hechos notables acaecidos en la república de Centroamérica desde el año 1821 hasta el de 1842, (1844), Guatemala, 1895.

MCREERY, David: "State Power, Indigenous Communities, and Land in Nineteenth-Century Guatemala, 1820-1920" en C. SMITH. Guatemalan indians and the State: 1540 to 1988, Austin, 1994.

MEJiA, Medardo: D. Juan Lindo. El Frente Nacional y el Anticolonialismo, Tegucigalpa, 1993.

Meléndez, Carlos: La Legislación indigenista de Costa Rica, México, 1957

MELENDEZ, Carlos: Documentos fundamentales del siglo xix, San José, 1978.

MELÉndez, Carlos (comp.): Mensajes presidenciales, San José, 1981.

MElÉnDez, Carlos: La Independencia de Centroamérica, Madrid, 1993.

MONTÚfAR, Lorenzo: Reseña histórica de Centroamérica, Guatemala, 1878-88.

PALMER, Steven: "A Liberal Discipline: Inventing Nations in Guatemala and Costa Rica", Tesis doctoral, Universidad de Columbia, 1990.

Peralta, Hernán G.: Las Constituciones de Costa Rica, Madrid, 1962.

PIEL, Jean: Sajcabaja. Muerte y resurrección de un pueblo de Guatemala, 1500-1970, Guatemala-México, 1989.

Pineda de Mont. Manuel: Recopilación de las leyes de Guatemala, Guatemala, 1869, t. 1.

PINTO SoRIA, Julio: Centroamérica de la coionia al Estado nacional (1800-1840), Guatemala, 1989

QuiJadA, Mónica: “ ¿Qué Nación? Dinámicas y dicotomias de la Nación en el imaginario hispanoamericano del siglo XIX" en M. QuIJADA y F.X. Guerra (coords.), "Imaginar la Nación", AHILA, n. 2 (1994).

Quijada, Mónica: Recopilación de las leyes emitidas por el gobierno democrático de la república de Guatemala, desde el 3 de junio de 1871 hasta el 30 de junio de 1881, Guatemala, 1881 , t. II.

Quluada, Mónica: "Revista Política sobre la historia de la Revolución de Nicaragua en Defensa de la Administración del ExDirector D. José Sandoval. Escrito por Pedro Francisco de la Rocha, Granada, 1847 ", Revista del Pensamiento Centroamericano, n. 180 (julio-septiembre, 1983).

Rivas, Anselmo: Nicaragua. Su pasado, Ojeada retrospectiva, Managua, 1936.

RodRiguez, Mario: "The Livingston Codes in the Guatemalan Crisis of 1837-1838", en M. HARRISON y R. WAUCHOPE (eds.), Applied Enlightenment: 19th Century Liberalism, New Orleans, 1972.

Rodriguez, Mario: El experimento de Cádiz en Centroamérica, 1808-1826, México, 1984.

Rodriguez Ruiz, Napoleón: Historia de las Instituciones juridicas salvadoreños, San Salvador, 1951.

ROMERO, Luis A. (comp.): El pensamiento conservador, Caracas, 1978.

Rosa, Ramón: Obra Escogida, Tegucigalpa, 1980.

Rosanvallón, Pierre: Le sacre du citoyen. Histoire du suffrage universel en France, París, 1996

Sáenz Carbonell, Jorge $F .:$ Los años del voto directo. D. Francisco María Oreamuno y la Cons titución de 1844, San José, 1992.

SalazAR, Orlando: El apogeo de la república liberal en Costa Rica, 1870-1914, San José, 1990.

Silva HeRnández, Margarita: “Desarrollo jurídico institucional del sistema electoral en Costa Rica, 1821-1870", Avances de Investigación, n. 5 (San José 1990).

TARACENA, Arturo: “Liberalismo y poder politico en Centroamérica", (1870-1929) en V. H. ACUÑA, Historia General de Centroamérica, Madrid, 1993, vol. IV.

VÁzQUEZ, Josefina Z: "Liberales y conservadores en México: diferencias y similitudes", Estudios Interdisciplinarios de América Latina y El Caribe, n. ${ }^{\circ}$ (enero junio 1997).

VEga Bolaños, Andrés: Gobernantes de Nicaragua. Notas y documentos, Managua, 1944

VEGA BOLAÑos, Andiés: Los acontecimientos de 1851. Notas y documentos, Managua:1945.

VELA, David: Barrundia ante el espejo de su tiempo, Guatemala, 1957. 
El debate entre liberales y conservadores en Centroamérica: Distintos medios..

WoodWARD, Ralph L.: «Pensamiento Científico y Desarrollo Económico en Centroamérica, 1860-1920", Revista del Pensamiento Centroamericano, $n .{ }^{\circ} 172-173$, (julio-diciembre, 1981).

WoOowaro, Ralph L.: "Orígenes económicos y sociales de los partidos políticos guatemaltecos (1773-1823)", Anuario de Estudios Centroamericanos, n. ${ }^{\circ} 1$ (1974).

WoOdWard, Ralph L.: Central America, a Nation Divided, Oxford University Press, 1985.

WoODWARD, Ralph L.: Rafael Carrera and the Emergence of the Republic of Guatemala, 18211871, Georgia, 1993

Wortman, Miles: Government and Society in Central America, 1680-1840, New York, 1982.

ZELAYA, Orlando: "Sociedad y política: Gobiernos liberales conservadores en el siglo XIX (18381875)" en O. ZelayA (comp.), Lecturas de Historia de Honduras. Antologia, Tegucigalpa, 1998.

Zelaya Goodman, Chester J.: El Bachiller Osejo, San José, 1971, vol. II. 